\title{
PLATOS FENICIOS DE OCCIDENTE
}

\author{
HERMANFRID SCHUBART \\ Instituto Arqueológico Alemán
}

\begin{abstract}
Los platos fenicios de barniz rojo presentan una evolución en el ancho del borde y en la relación entre diámetro y anchura de borde que permite realizar una secuencia cronológica que fecha los poblados fenicios e indígenas del Mediterráneo occidental.
\end{abstract}

The Phoenician red slip plates present a chronological evolution of the wide of the rim and the relationship between the diameter and the wideness of the rim that allows propose a chronological sequence which date the Phoenician and indigenous settlements in Western Mediterranean.

La versión original alemana de este trabajo fue redactada en 1975 y se publicó en 1976 ${ }^{1}$. La traducción al castellano se preparó y se presentó también en el Symposium Internacional de Prehistoria Peninsular celebrado en Córdoba. Desgraciadamente, al organizador del symposium, al venerado colega y amigo Juan Maluquer de Motes, la vida no le dio tiempo de publicar las actas del Symposium. Así, el manuscrito castellano quedó inédito mientras se entregaron varias copias a los colegas interesados.

Últimamente, ha surgido la idea de publicar esta versión castellana (mejorada), lo que parecía ya entonces al autor de este artículo una obligación frente a los colegas españoles y lo que hoy -30 años después- le parece todavía una posibilidad con ciertas ventajas entre otras para reconstruir la historia de la investigación sobre la cronología de los asentamientos fenicios y sobre la diferenciación de lo fenicio y de lo tartésico.

Por otro lado, a la vista de posteriores trabajos propios, de una inmensa cantidad de hallazgos nuevos $y$, también, en vista de una amplía bibliografía sobre platos fenicios de occidente -este "fósil indicador"-, el autor no se ve en condiciones de actualizar un trabajo que se redactó tanto tiempo atrás. Habría que escribirlo de nuevo. Por tanto, el autor se limita a citar los últimos estudios referentes al tema (Barceló et alii, 2001, 1459 ss.; Mayet y Tavares Da Silva, 2000; Maass-Lindemann, en prensa).

No obstante, unas reproducciones de figuras publicadas en 1983 (Schubart, 1982a,
220, Abb. 11; 228, Abb. 17; 229, Abb. 18; Schubart, 1982b, 83, fig. 11; 98, fig. 17; 99, fig. 18 ), especialmente expresivas para la tipología y la importancia cronológica de los platos fenicios, le han parecido útiles al editor. Estas reproducciones aparecen aquí como las figuras 6, 18 y 19 .

El autor agradece muy de corazón a los editores, la idea de revisar la traducción y de publicar este trabajo procedente de una fase ya "pre" o, por lo menos, "protohistórica" del autor.

Moraira, Otoño 2004

Una de las formas principales de la cerámica fenicia del ámbito mediterráneo occidental son sin duda alguna los platos de cerámica roja, aunque durante mucho tiempo -y en parte aun hoy- desempeñaron sólo un papel secundario en los estudios dedicados a la cerámica fenicia y púnica ${ }^{2}$. D.B. Harden hizo una primera aportación al papel desempeñado por los platos fenicios de Occidente en su estudio

\footnotetext{
${ }^{1}$ La versión castellana del texto original alemán (Rivista di Studi Fenici, 4 (2), 1976) se debe a doña María Luisa Vázquez de Parga de Cortés.

${ }^{2}$ El presente trabajo ha sido sugerido por el estudio del material de los poblados fenicios de la zona de Torre del Mar (Málaga). Los resultados obtenidos han sido largamente discutidos con el Prof. Dr. Hans Georg Niemeyer y la Dra. Gerta Maass-Lindemann, los amigos y colegas de las excavaciones de Torre del Mar, a los que el autor quiere mostrar su permanente agradecimiento.
} 


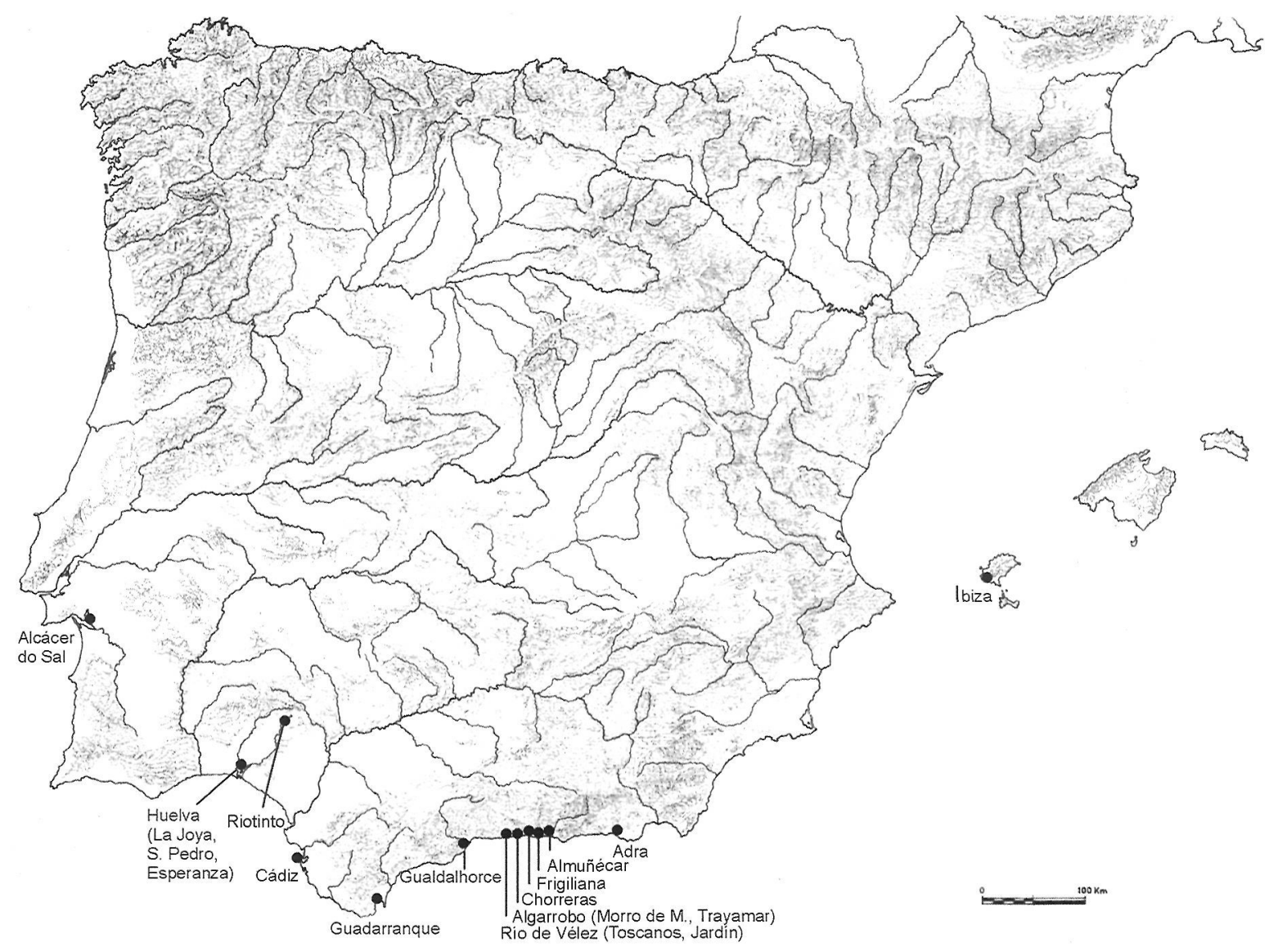

Figura 1: Yacimientos fenicios de Andalucía.

sobre el santuario de Tanit de Salambo (Harden, 1937, 82 s.), en Cartago, donde se utilizaron reiteradamente platos como tapaderas de urnas. Los platos del santuario de Tanit, el más antiguo de los cuales fue fechado por Harden ya en el siglo VIII (Harden, 1937, 83, fig. 7a), habían sido escogidos, sin embargo, para su función de tapadera y no son, por tanto, representativos de los platos fenicios de Occidente en general; son considerablemente más pequeños y de mayor grosor que el resto de los platos conocidos (Niemeyer y Schubart, 1975, 42 , n. 35). Cintas, en su tratado fundamental sobre la cerámica púnica, se apoya sólo en los resultados de Harden y no se ocupa del desarrollo de los platos, de los que dice que tuvieron también su historia en Cartago, pero acaba afirmando que no pudieron alterar su forma porque siempre se utilizaron para el mismo fin, al parecer profano (Cintas, 1950, 489s). Asimismo, en el trabajo de Bisi tampoco aparecen los platos entre las formas principales de la cerámica fenicio-púnica (Bisi, 1970, lám. 2), aun cuando dentro del marco del estudio se reseñan extensamente distintos yacimientos feni- cios de Occidente con numerosos hallazgos de platos (Bisi, 1970, 93 s., 103 s.). Ni siquiera en las figuras que reseñan material del Norte de Africa o de la Península Ibérica está representado algún plato (Bisi, 1970, láms. 14, 16-19), a pesar de que en las citadas publicaciones aparecen reproducidos muchos de ellos. La ausencia del plato entre las formas principales de Bisi (Fernández Gómez, 1971, 421-422) es tanto más de lamentar cuanto que su cuadro de formas principales, aun a pesar de eso, se considera fundamental (Tarradell y Font, 1974, 152, fig. 44).

Esta exclusión de los platos fenicios de Occidente parece deberse en primer lugar al hecho de que en los hallazgos de tumbas de Cartago, Sicilia y Cerdeña el número de platos era relativamente escaso, si se prescinde de los que se utilizaron como tapaderas de urnas o como platillos de lucernas. Además, los estudios estratigráficos de poblados eran extraordinariamente escasos o faltaban por completo. Pero este cuadro varió por completo en el Occidente fenicio en los años de 1950 a 1970, los veinte años transcurridos entre las publicacio- 


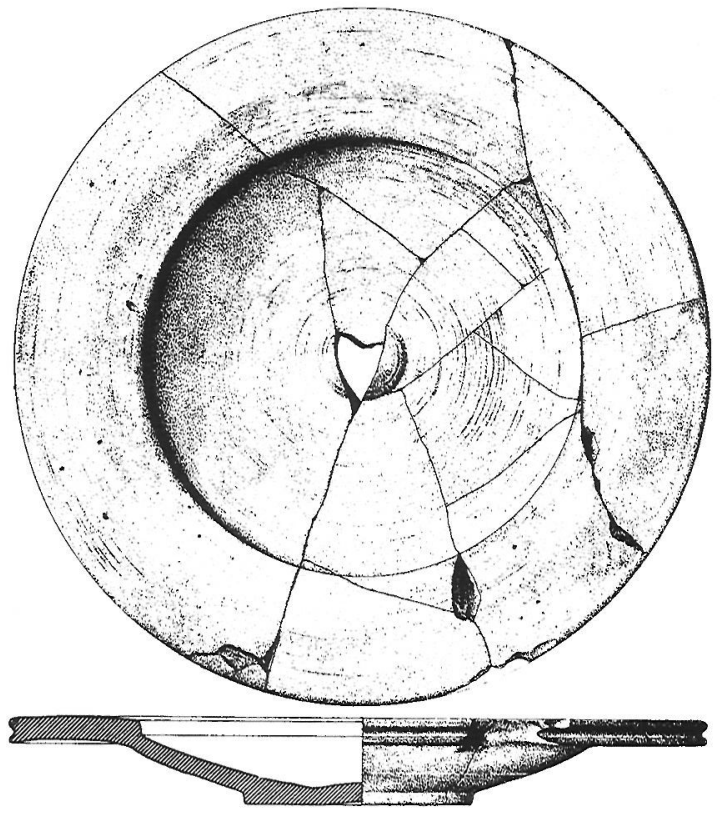

Figura 2: Plato de la casa E (fase IV). Toscanos (Torre del Mar, Málaga) (Niemeyer y Schubart, 1968, 89, fig. 7.1).

nes de Cintas y Bisi. Tanto en Marruecos como en España se estudiaron varios poblados entre cuyo material se encontraron fragmentos de platos, incluso en número sorprendentemente grande. Además las necrópolis fenicias de Occidente excavadas en Andalucía (Fig. 1), así como también la de Rachgoun, en Argelia, han mostrado claramente que los platos podían formar parte de los ajuares sepulcrales.

Entre 1970 y 1975 se produjo un aumento considerable en nuestras fuentes. Vamos a presentar aquí como tipo el plato fenicio, que es sin duda una de las formas más importantes de la cerámica fenicia de Occidente (Fig. 2). Sobre una base plana o también retraida, a veces ligeramente marcada, se levanta el cuerpo del vaso muy abierto de perfil cónico o en línea curva. La parte honda, o sea el plato propiamente dicho, está casi siempre rodeada de un borde más o menos ancho, que en la mayoría de los casos está claramente marcado, que puede ser de forma horizontal o en curva y es de importancia decisiva para la determinación de la forma. Los diámetros oscilan entre 20 y $30 \mathrm{~cm}$, alcanzando los valores extremos de 15 a $45 \mathrm{~cm}$. La arcilla, de una textura no demasiado dura, lleva generalmente, sólo en la parte superior del plato, un engobe rojo, que a veces se extiende también por parte de la cara inferior. Es muy raro que un motivo pintado interrumpa el engobe que normalmente cubre la superficie (Fig. 3) (Niemeyer y Schubart, 1975, lám. 7, 418a; Lindemann, Niemeyer y Schubart, 1972, 141, fig. 8). La coloración del engobe puede variar de las tonalidades rojas, que son las más generales, a tonos anaranjados o castaños. La superficie, después de la aplicación del engobe y antes de la cocción, se bruñe finamente, por regla general. Los platos pertenecen, junto con las jarras (Almagro Gorbea, 1972, 180 s.; Niemeyer y Schubart, 1975, 129 s.; Maass Lindemann, 1982), un determinado tipo de ánfora (Niemeyer y Schubart, 1975, 133), un gran número de lucernas (Niemeyer y Schubart, 1975, 127 s.), con incensarios (Niemeyer y Schubar, 1975, 131 s.), y distintas formas de cuencos (Niemeyer y Schubart, 1975, 37, fig. 2; Aubet, Maas-Lindemann y Schubart, 1975, 137 s.), a la llamada cerámica roja, que puede considerarse como la vajilla de mesa más fina en la época de la colonización fenicia en el ámbito occidental del Mediterráneo desde el siglo VIII y durante todo el siglo VII a. de J.C. y, que únicamente en el siglo VI fue desplazada de esa función por la cerámica pintada, que se va situando en primer término. Como elemento de la vajilla fina aparece, por tanto, también el plato en los ajuares funerarios, tanto como ofrenda en la sepultura misma como encima de ella.

Este peculiar papel desempeñado por el plato en Occidente se hizo ya evidente en la necrópolis fenicia de Almuñécar (Granada), excavada y publicada por M. Pellicer Catalán (1963a y 1963b, 9 s.). En cinco sepulturas (2, $12,13,15$ y 19B) aparecen aquí platos de ce-

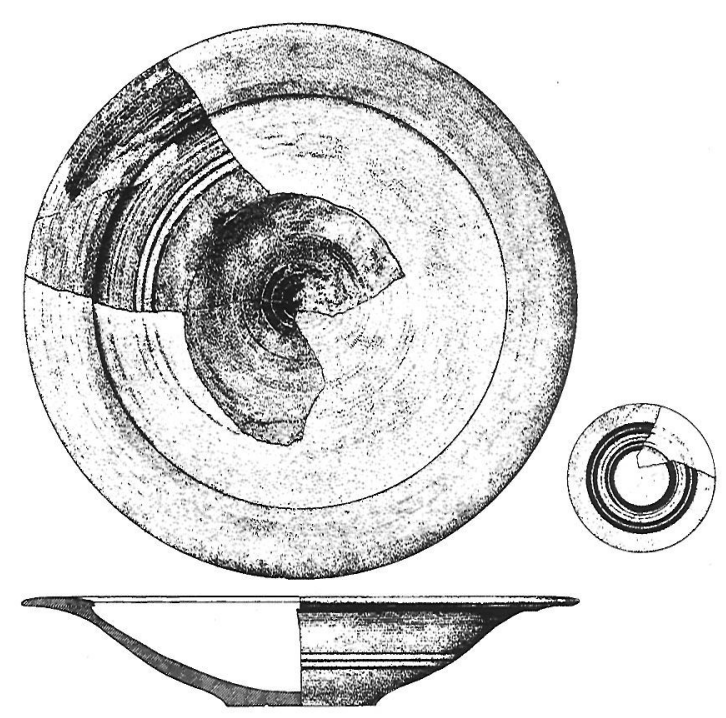

Figura 3: Plato del corte 14 (TM 71/61+63). Toscanos (Torre del Mar, Málaga) (Lindemann, Niemeyer y Schubart, 1972, fig. 8.1). 


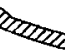

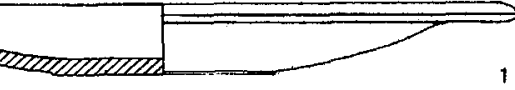

A
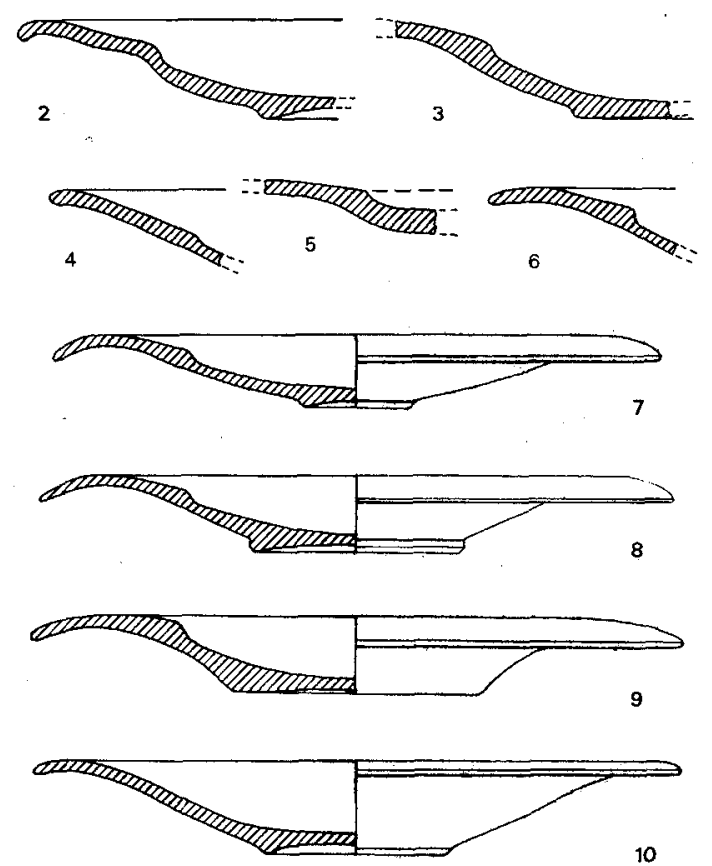

B

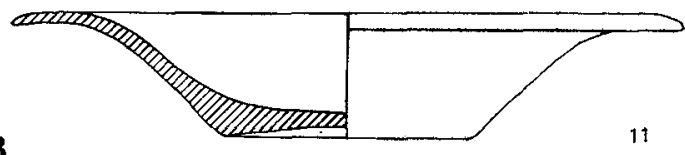

Figura 4: A: Rachgoun (Argelia) (Vuillemot, 1955, lám. 8.11). B: Almuñécar (Granada), 2b y $6 b$ (sep. 17), 3b y $5 b$ (sep. s/ n), 4b (sep. 19B, con las kotyles protocorintias), 7b (sep. 13), 8b (sep. 12), 9b (sep. 15), 10b (sep. 16), 11b (sep. 17) (Pellicer, 1963b, 8, fig. 10-19).

rámica roja como elementos del ajuar funerario (Fig. 4: B). Además se encontraron varios fragmentos en la sepultura 7 entre el relleno, como testigos del hábitat cercano o -lo que es más verosímil- como restos de ofrendas depositadas en posición secundaria (Fig. 4: B. 2 y 6 ). Por dos kotyloi protocorintios, cuya fecha de fabricación, aun teniendo en cuenta la diferencia cronológica entre ambos, se encuentra en época anterior al 675 a. de J.C., se fechó con seguridad el plato de la sepultura $19 \mathrm{~B}$ en la primera mitad del siglo VII a. de J.C. (Pellicer, 1963b, fig. 19/5).

Un conjunto de hallazgos de platos de cerámica roja mucho mayor dieron las excavaciones de la factoría fenicia de la isla de Mogador (Marruecos) realizadas por A. Jodin $(1966,77 \mathrm{~s}$.$) . Jodin establece una distinción$ entre los platos con forma sencilla de borde, de los que se encontraron "plusieurs dizaines", de fragmentos de borde, y los platos con borde acanalado, que aparecieron en triple número que los de borde sencillo (Fig. 5: B). En total debieron encontrarse en Mogador más de un centenar de fragmentos de borde de platos reconocidos como tales, de los que Jodin sólo reproduce cinco en fotografía y dos en dibujo, no dando desgraciadamente tampoco más que las medidas de 10 platos (Jodin, 1966, 83, lám. 21: 22, fig. 15). Jodin considera este conjunto de materiales como más o menos uniforme y lo coloca en el siglo VII a. de J.C.

Grandes cantidades de platos fenicios debieron salir a luz en las excavaciones de Lixus, también en Marruecos, donde se consiguió obtener la primera referencia de un desarrollo cronológico de la forma de los platos, aun cuando faltó la comprobación estratigráfica (Jodin, 1966, 21 s.; Tarradell com. pers.) ${ }^{3}$.

La necrópolis de Rachgoun, situada como dato significativo -lo mismo que Mogador- en una de las islas existentes frente a la costa, dio un grupo bastante grande de platos de cerámica roja (Vuillemot, 1955, 19.48, lám. 8:11) de los que desgraciadamente sólo se reprodujo uno (Fig. 4: A. 1 diám. $29 \mathrm{~cm}$; borde $5 \mathrm{~cm}$ ). Los platos tenian en su mayoria engobe rojo y servían de tapadera a las características urnas pintadas de Rachgoun. La necrópolis de Rachgoun se utilizó en los siglos VII/VI a. de J.C.; la sepultura 11 debió corresponder, con otros enterramientos, aun al siglo VII a. de J.C., a favor de lo cual habla también el plato de cerámica roja.

En las excavaciones del Instituto Arqueológico Alemán en la colonia fenicia de Toscanos (Torre del Mar, Málaga), el primer sondeo dio ya unos 500 fragmentos de platos

\footnotetext{
${ }^{3}$ Después de haber concluido el manuscrito recibió el autor, como contestación a su consulta por carta, la siguiente información del excavador Prof. Dr. M. Tarradell, de Barcelona: "El gran problema de Lixus es que, además de la fragmentación de los materiales, no pudimos hallar estratigrafias suficientemente 'limpias' y extensas como para poder establecer desarrollos tipológico-cronológicos seguros. Desde luego hay indicios que los platos de borde más ancho son antiguos, pero quizás posteriores a los de borde más estrecho; es decir, que hay una primera etapa sin borde ancho. Pero no dispongo de datos suficientes para elevar esta impresión a conclusiones definitivas (...) dadas las condiciones del yacimien. to, que por haber vivido tantos siglos sufrió en los estratos bajos".

${ }^{4} \mathrm{El}$ dibujo del perfil del plato de la sepultura 11 presenta, debido a la gran reducción del modelo, un cierto factor de inseguridad. También las medidas mencionadas en el texto se han calculado con ayuda de la escala del dibujo original.
} 

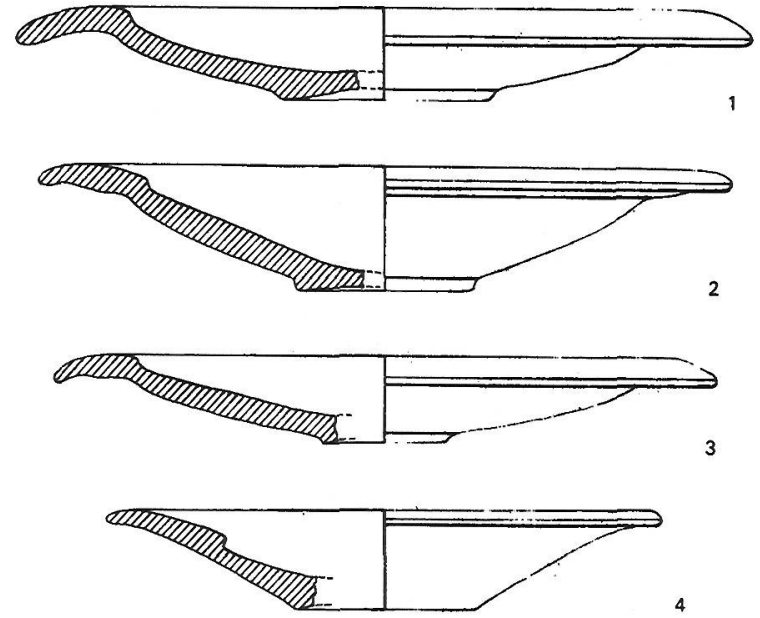

4

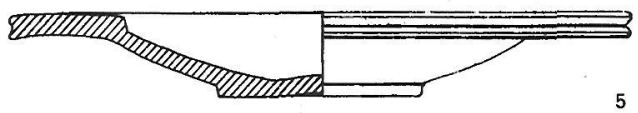

A

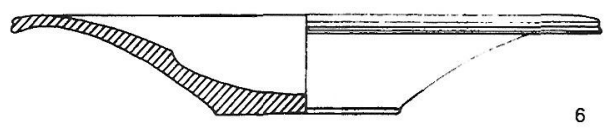

6

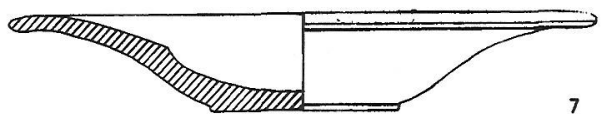

\section{B}

Figura 5: A: Toscanos (Torre del Mar, Málaga), campañas de 1964/1967. 1a (estrato I, 137), 2a (estrato II, 423), 3a (estrato II, 418), 4a (estrato IVb, 886), 5 casa E (Niemeyer y Schubart, 1968, 9, fig. 7; Niemeyer y Schubart, 1969: láms. 10 y 12). B: Mogador (Marruecos) (Jodin, 1966, 1, fig. 15.1).

de cerámica roja (Niemeyer y Schubart, 1966, 82 s., lám. 7.279, 418a, 561; láms. 10-12). La observación del desarrollo de las formas dentro del marco de la sucesión de estratos de Toscanos permitió, entre otros resultados, conocer que desde los estratos más antiguos a los más modernos el ancho del borde de los platos va en aumento (Fig. 5: A; Fig. 7). Platos con bordes estrechos, de menos de $3,5 \mathrm{~cm}$, se encuentran sólo en los estratos I y II, o sea antes de la construcción del edificio de almacén C, cuya edificación corresponde al estrato III. Por otro lado, los platos con anchos de borde de $5,5 \mathrm{~cm}$ para arriba sólo aparecen en los estratos IVa hasta IVf, que se formaron después de haberse levantado el edificio de almacén. De todos modos hay que comprender que con la actividad constructiva allí observada, frag- mentos tempranos de los estratos más antiguos llegaron a los más modernos.

A resultados análogos llevaron los estudios paralelos de los cocientes entre diámetro y ancho de borde (Fig. 8), de los que se deduce que el ancho del borde mantiene una determinada proporción con el diámetro del plato, observación que adquiere mayor importancia al comprobar que también los diámetros de los platos experimentan un desarrollo determinado, observándose en ellos al principio un aumento de tamaño (Niemeyer y Schubart, 1969, 86 s., fig. 3) y finalmente -aproximadamente desde el siglo VI- una nueva disminución del diámetro del plato (Fig. 8).

Las excavaciones de 1967, 71 y 73 ampliaron considerablemente el material, con lo que el número de fragmentos de platos de Toscanos multiplicó considerablemente el numero de partida de 1964. Los estudios de este material no se han concluido aun, pero confirman, sin embargo, los resultados obtenidos con el material de 1964, especialmente con el añadido del estrato $V$, descubierto en 1967 que, con anchos de borde de $6,2,6,8$ y $6,9 \mathrm{~cm}$ sobrepasa con mucho los valores extremos alcanzandos en 1964 (Niemeyer y Schubart, 1968, 76 s. y 1969; Lindemann, Niemeyer y Schubart, 1972, 125 s.; Maass Lindemann, 1982).

Un dato para fijar la cronología de la estratigrafía de Toscanos y con ella la cronología de los platos fenicios de Occidente nos lo da el hallazgo de unos fragmentos de kotyloi protocorintios del primer cuarto del siglo VII a. de J.C. en los estratos IVa y IVb (Niemeyer y Schubart, 1968, 91, lám. 23a; Lindemann, Niemeyer y Schubart, 1972, 143, lám. 24). Esta datación se confirma también con los fragmentos de un ánfora SOS ática en el estrato IVb (Niemeyer y Schubart, 1969, 116, lám. 38. 1023). Como la datación del conjunto de estratos IV a/b está asegurada por fragmentos de nueve kotyloi protocorintios por lo menos (Rouillard com. pers.) ${ }^{5}$, no puede tampoco pensarse en una pervivencia demasiado larga de estos vasos, sino que hay que suponer que el conjunto de estratos IV a/b se formó también en el primer cuarto del siglo VII. El edificio de almacén de Toscanos se fecharía con eso hacia el 700 a. de J.C. y los estratos I y II debieron, de acuerdo con ello, alcanzar el siglo VIII, por lo menos en su segunda mitad.

${ }^{5}$ Estoy sumamente agradecido al Sr. Pierre Rouillard de la Casa de Velázquez, de Madrid, por su amable asesoramiento. 


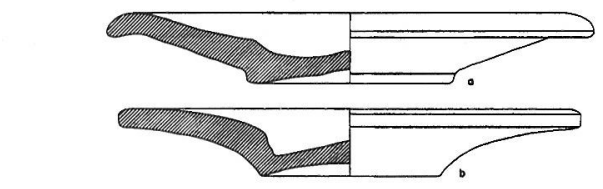

$1976 \mathrm{~V} / \mathrm{VI}$
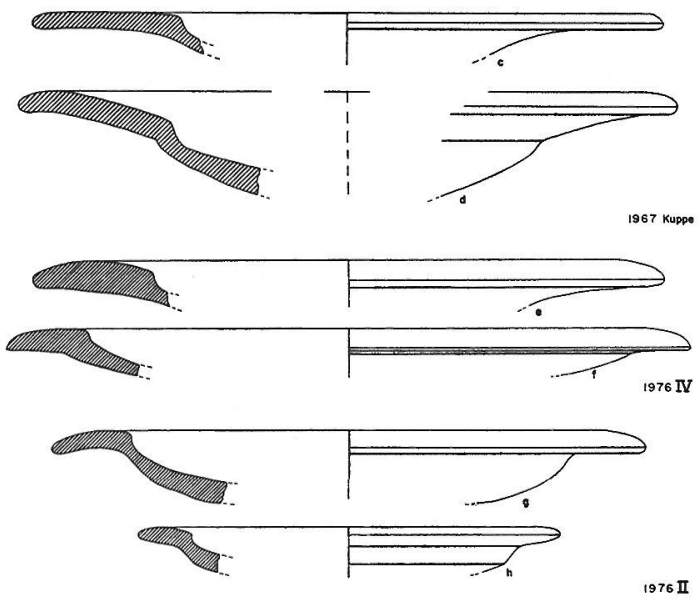

1976 II
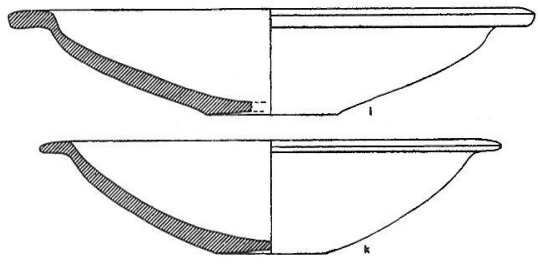

1976 I

Figura 6: Morro de Mezquitilla (Algarrobo, Málaga). Fragmentos de platos de la estratigrafía de los cortes 7-8 (1976, estratos BI-VI), completada por medio de dos platos de una fase del poblado no encontrada en el corte $7 / 8 \mathrm{de}$ finales del siglo VII a. de J.C., de la cima de la colina, campaña de 1967, comprobación estratigráfica definitiva de la cronologia de los platos (Schubart 1982a: 220 fig. 11).

Unos kilómetros al Este de Toscanos se encuentra, a orillas del río Algarrobo, en lo alto del Morro de Mezquitilla, otro establecimiento fenicio y enfrente, sobre las alturas de la orilla occidental, la necrópolis de hipogeos de Trayamar; ambos fueron estudiados en 1967 por el Instituto Arqueológico Alemán (Niemeyer y Schubart, 1975). Los platos de la factoría del Morro (Fig. 6) no son demasiado numerosos, pero nueve ejemplares, cuyos anchos de borde están entre 3,1 y $4,0 \mathrm{~cm}$, pertenecen, si se sigue el esquema de Toscanos, a un período relativamente antiguo y sólo dos, con anchos de borde de 5,7 y $6,0 \mathrm{~cm}$, se relacionan con la época tardía de Toscanos (Niemeyer y Schubart, 1975, 41 s.).

En las sepulturas de cámara de Trayamar se encontraron, por el contrario, platos con bordes mucho más anchos. Un plato de la cámara 4 presenta un ancho de borde de $7,7 \mathrm{~cm}$ (Fig.
9: 2), otro, del dromos de la sepultura 1, que debió llegar al sitio donde fue encontrado en el momento del cierre de la cámara, tiene un ancho de borde de 6,9 cm (Fig. 9: 1). Estas dos medidas se encuentran por encima del máximo de 5,8 establecido para Toscanos 1964 y entre los valores máximos de Toscanos 1967 o aun por encima de ellos.

La mayor parte de los cerca de 400 fragmentos de platos de Trayamar (Fig. 9: 3-6; Fig. 10: 1-8) proceden de estratos que pueden haberse formado lo más pronto durante el periodo de ocupación de la sepultura 4, en su mayor parte incluso después del cierre de la misma, pero sobre todo del estrato 8 , situado directa-

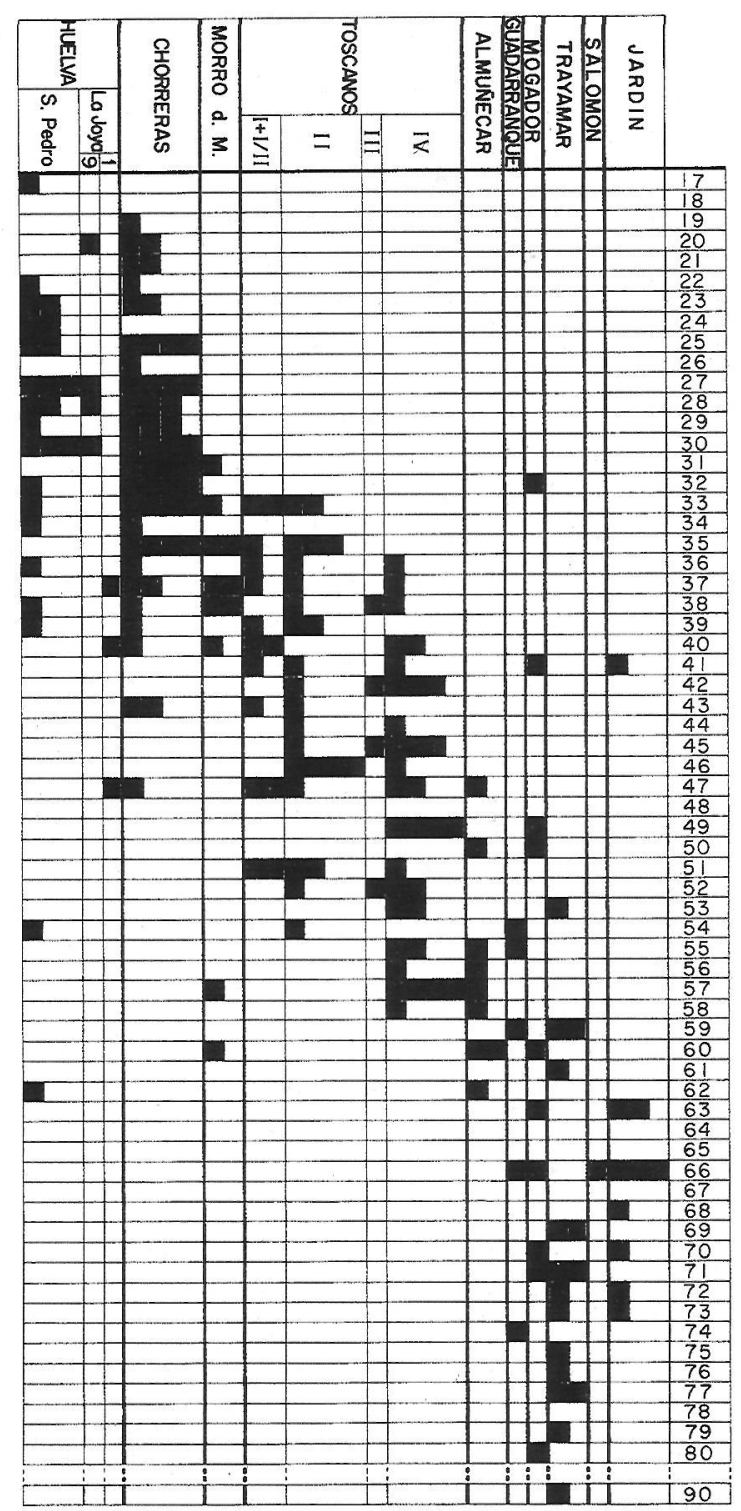

Figura 7: Platos de cerámica roja con anchos de bordes en $\mathrm{mm}$ 


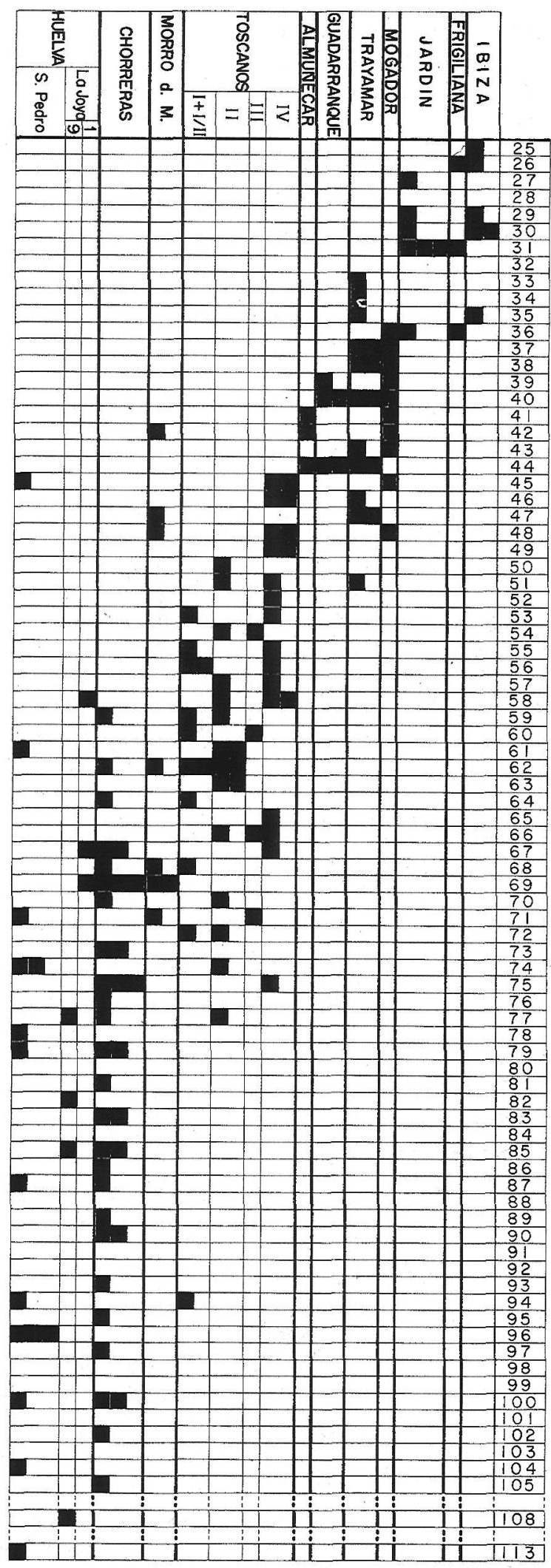

Figura 8: Resultado de dividir los diámetros de los platos de cada yacimiento por los anchos máximos de sus bordes. mente debajo de la superficie. El origen de este conjunto de hallazgos se explica únicamente relacionándolo con las ceremonias celebradas en la sepultura; los hallazgos se consideran por tanto ofrendas, que hay que pensar servirian de recipientes para alimentos o bebidas, a no ser que, por la colocación del plato hallado en el dromos de la sepultura 1, se interpretase este plato como vaso-ofrenda. En todo caso, los platos desempeñaron un papel peculiar en una ceremonia realizada en la sepultura, probablemente un banquete funerario. Si de todo ello pudiese deducirse que los actos relacionados con las ofrendas en la sepultura empezaban con la ocupación de la cámara, pero se continuaban más allá de su cierre, el conjunto de platos del estrato 8 adquiere un interés cronológico especial. Los anchos de los bordes de los platos de este conjunto de hallazgos se extienden desde $5,3 \mathrm{~cm}$, ancho que aun sería posible en Toscanos, hasta $9,0 \mathrm{~cm}$, aunque es sorprendente que la mayoría de los platos tengan un borde más estrecho que el plato 633 de la misma cámara sepulcral 4 (Fig. 9: 2). Los
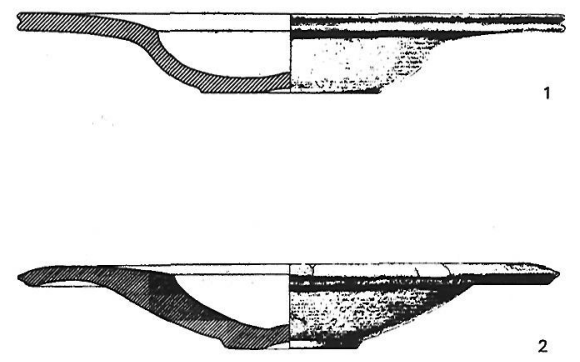

2

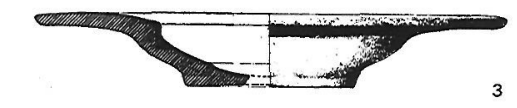

3
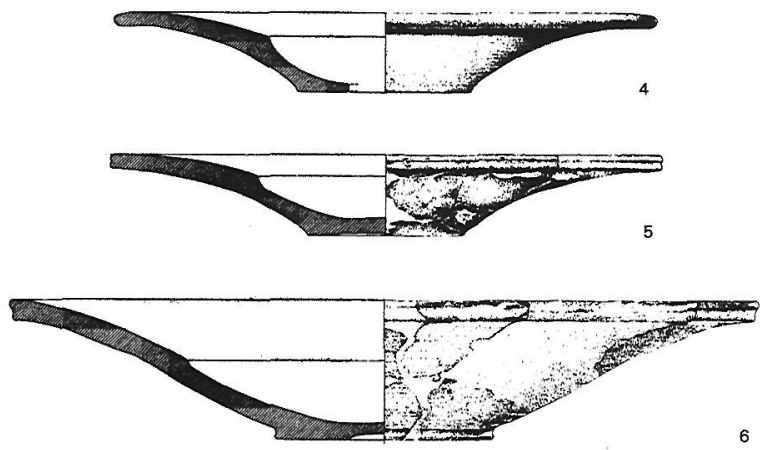

Figura 9: Trayamar (Algarrobo, Málaga). Campañas de 1967/ 1969. 1 (sep. 1, dromos 568), 2 (sep. 4, cámara 633), 3-6 (sep. 4, estrato 8, 709, 712-713, 715) (Niemeyer y Schubart, 1975, láms. 14, 18, 21-23). 


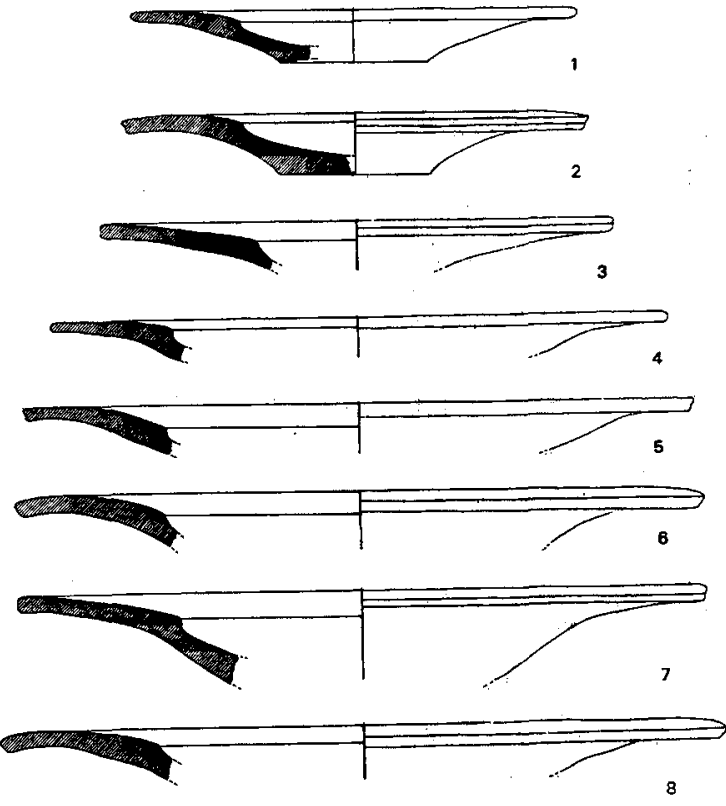

Figura 10: Trayamar (Algarrobo, Málaga). Campaña de 1967. Sepultura 4 , estrato $8,1(710), 2(711), 3(721), 4(728), 5$ (717), 6 (726), 7 (727), 8 (725) (Niemeyer y Schubart, 1975, lám. 21).

enterramientos más antiguos de la sepultura 4, a los que este plato parece corresponder, serían por tanto más modernos que los estratos IV a/b de Toscanos y deberían por ello datarse hacia mediados del siglo VII a. de J.C. o en su segunda mitad (Fig. 7; Fig. 8) (Niemeyer y Schubart, 1975).

Finalmente, las excavaciones subvencionadas por el Instituto Arqueológico Alemán en Chorreras pusieron al descubierto otro establecimiento fenicio en una elevación de la orilla directamente sobre el Mediterráneo (Aubet, Maas-Lindemann y Schubart, 1975, 137 s.). Un tramo de calle y varias plantas de casas dan una idea de la forma del poblado dentro del marco de una factoría de este tipo. La proporción de los fragmentos de platos volvió a resultar grande en relación con la totalidad del material hallado. Los anchos de los 54 fragmentos de borde que pudieron considerarse como tales con seguridad se encuentran sorprendentemente entre 1,9 y $4,0 \mathrm{~cm}$; sólo tres fragmentos los sobrepasan alcanzando los 4,7 $\mathrm{cm}$ (Fig. 11). En Chorreras predominan por tanto con mucho los bordes estrechos y señalan con ello una fecha relativamente antigua para este establecimiento. Si se toma como base la datación de principios del siglo VII establecida por la importación de cerámica protocorintia y ática para los estratos IVa y $b$ de Toscanos y las sepulturas de Almuñécar, hay que señalar con grandes probabilidades una fecha en ple- no siglo VIII para el comienzo de Chorreras (Fig. 7; Fig. 8).

Para los establecimientos de Chorreras y del Morro de Mezquitilla, relacionados ambos con la desembocadura del Algarrobo, se plantea la cuestión de la relación cronológica de los dos lugares entre sí, así como con la necrópolis de Trayamar. En cuanto a posición geografica, el Morro de Mezquitilla es sin duda el que ocupa la típica situación de factoría, directamente en la desembocadura del rio y frente a la necrópolis de Trayamar. Verdad es que esta valoración de una colina bastante baja en la inmediata vecindad de la desembocadura del río como posición especialmente favorable para el establecimiento de una factoría fenicia se
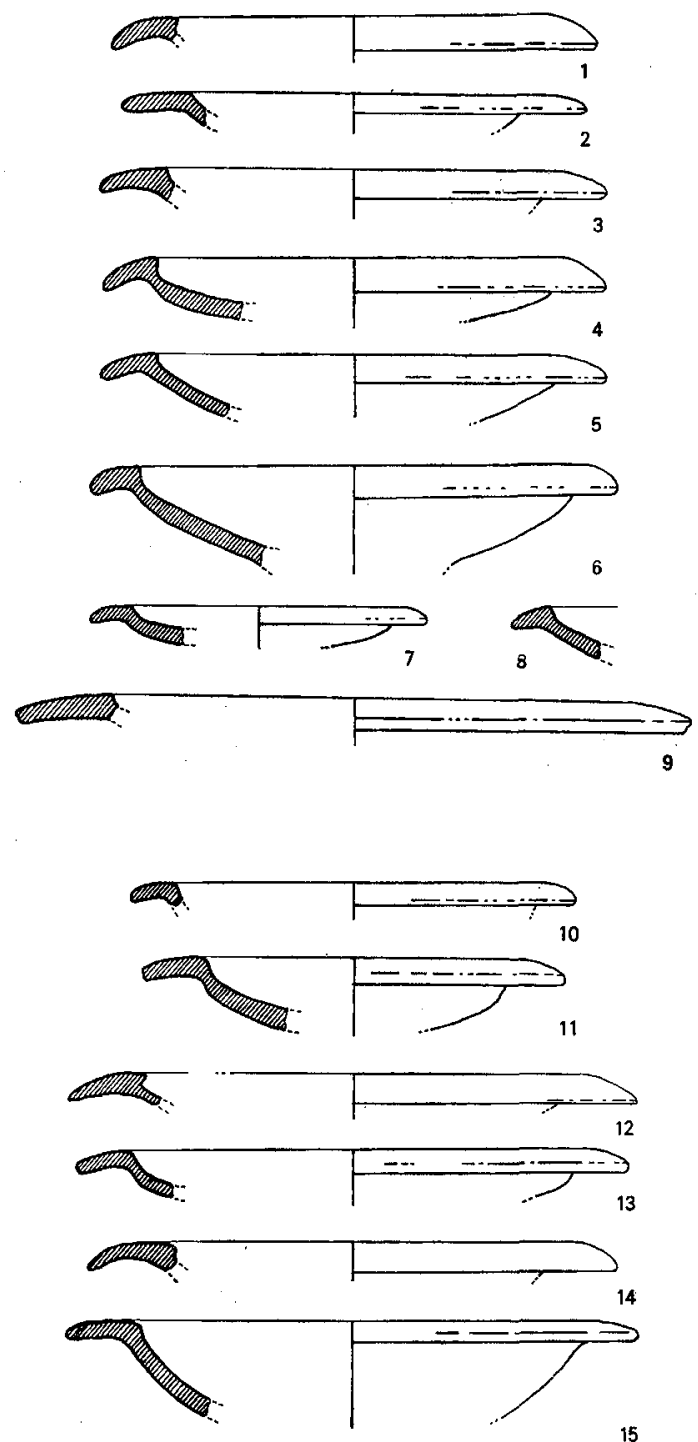

15

Figura 11: Chorreras (Torre del Mar, Málaga). Campaña de 1974. $1(8), 2(15), 3(9), 4(20), 5(3), 6(1), 7(13), 8(10), 9$ (17), 10 (31), 11 (22), 12 (43), 13 (46), 14 (29), 15 (37) (Aubet, Maass-Lindemann y Schubart, 1975, figs. 4-5). 

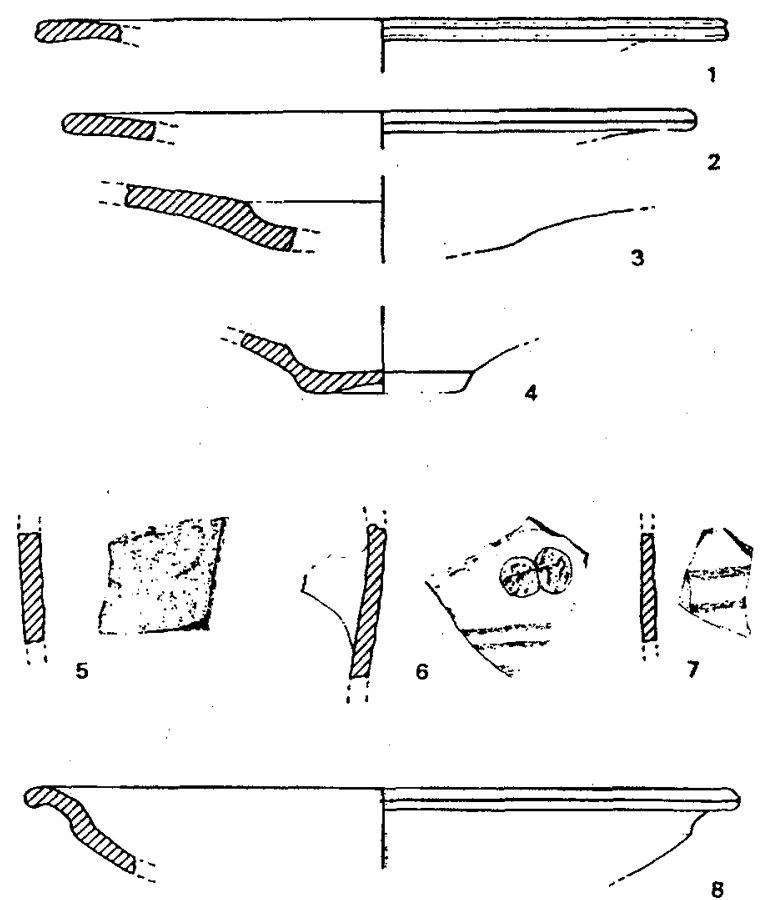

A
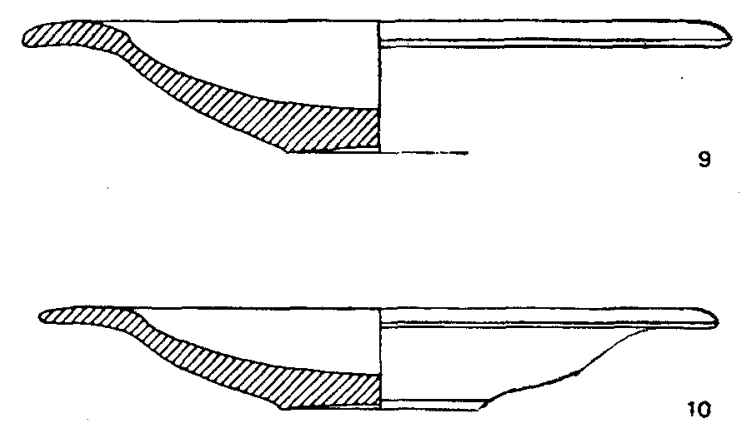

B

Figura 12: A: Abdera (Adra, Almeria). B: La Joya (Huelva) 9 10 (sep. 1).

basa en las observaciones que hasta el momento se han hecho de establecimientos mucho más recientes aparecidos por ahora. Sobre todo la datación de los platos evidencia que Chorreras es un establecimiento especialmente temprano, al parecer, en comparación con el Morro, el más antiguo, lo que sin embargo se vería con gusto confirmado con ulteriores excavaciones en el Morro. A juzgar por los hallazgos realizados por ahora (Fig. 7; Fig. 8), la necrópolis de Trayamar parece pertenecer más bien al poblado del Morro, donde junto a bordes de platos más estrechos aparecen dos más anchos, con lo que caen dentro del margen de Trayamar y no está relacionada con el estable- cimiento de Chorreras, en el que falta por completo la correspondiente fase más reciente.

En el marco cronológico arriba descrito (Fig. 7 ; Fig. 8), que desde un establecimiento antiguo en Chorreras y otro algo más tardio en el Morro de Mezquitilla, pasando por los estratos de Toscanos, lleva al conjunto de ofrendas de Trayamar 4, se insertan los platos de Almuñécar, con anchos de borde entre 4,7 y $6,2 \mathrm{~cm}$, como aproximadamente contemporáneos de los estratos más tardíos de Toscanos. Las sepulturas de Almuñécar debieron ser, a juzgar por la cronología de los platos, poco más antiguas que las de Trayamar. A favor de ello hablan también otros argumentos, como la cronología de las jarras de boca de seta (Niemeyer y Schubart, 1975, 129 s.). Con esta estructura cronológica no concuerdan del todo los conjuntos de hallazgos de Toscanos IV a/b y Almuñécar 19B, fechados con toda seguridad en el primer cuarto del siglo VIl a. de. J.C. por las piezas protocorintias de importación y que resultan por tanto contemporáneos entre sí. Esta aparente contradicción -la diferencia de fecha dentro del marco de la cronología de los platos es en sí realmente mínimapuede sin embargo probablemente aclararse por el hecho de que los vasos protocorintios de Toscanos, afines a la vajilla de mesa y por ello más usados, llegaron al estrato de hallazgos con anterioridad a los dos kotyloi de Almuñécar, a los que evidentemente debe reconocérseles una vivencia más larga (vide supra) y que junto con un plato más desarrollado debieron llegar a la sepultura aproximadamente hacia mediados del siglo.

Dentro del marco de la historia de la investigación hay que mencionar los trabajos de M. Fernández-Miranda Fernández y L. Caballero Zoreda en el Cerro de Montecristo, cerca de Adra (Almería). Las excavaciones en sí, que se concentraron en la cima de la colina, no dieron ningún hallazgo que fuese anterior al siglo IV a. de J.C. Los hallazgos más antiguos de cerámica griega tampoco pudieron hacer que se fijase una fecha anterior a la de finales del siglo $\mathrm{V}$ como el momento más antiguo del establecimiento (Fernández-Miranda y Caballero, 1975, 195 s., 216; Schubart, 1969, n. 13; Schubart, 1973, 2). Precisamente este hallazgo de fragmentos griegos parece haber influido en los excavadores para que pensasen en la posibilidad de que una colonia griega hubiese precedido al establecimiento púnico (Fernández-Miranda y Caballero, 1975). En 1968/ 1970 pudieron sin embargo recogerse en la 


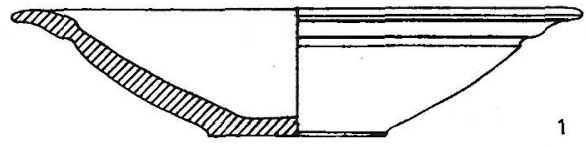

1
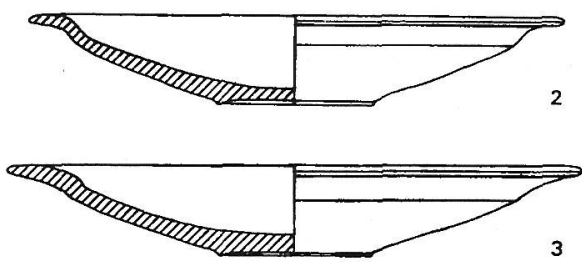

3

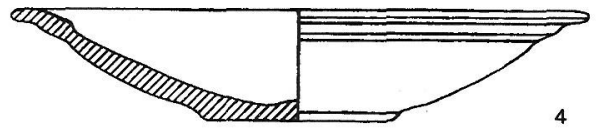

A
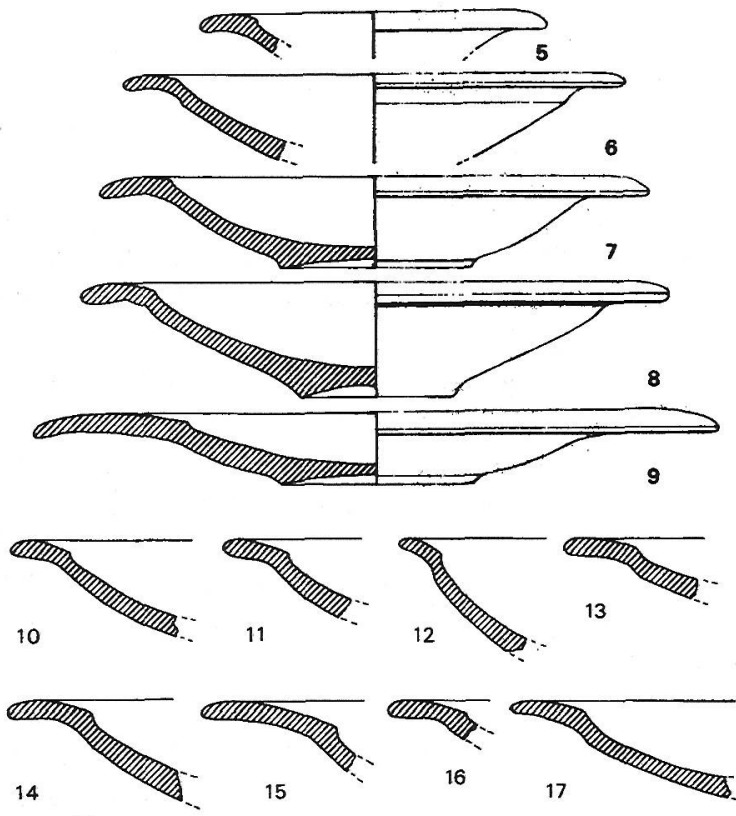

B

Figura 13: A: La Joya (Huelva). Campañas de 1966/1967. 14 (sep. 9) (Garrido 1970: 53 s., figs. 38 y 39.1-3). B: Cabezo de San Pedro (Huelva). 5 (14f), 6 (14j), 7 (14a), 8 (14b), 9 (14n), 10 (14c), $11(14 \mathrm{~d}), 12(14 \mathrm{e}), 13$ (14g), 14 (14i), 15 (14j), 16 (14h), 17 (14m) (Blázquez, Luzón, Gómez Toscano y Clauss, 1970, lám. 14).

pendiente oriental del Cerro Montecristo, donde con la construcción de bancales fueron cortados estratos más antiguos conservados, al igual que en Toscanos, únicamente en la pendiente, fragmentos superficiales entre los que habia varios que correspondían al horizonte de los establecimientos fenicios (Fig. 12: A), especialmente dos fragmentos de platos de cerámica roja, uno de los cuales, con un ancho de borde de más de $4,5 \mathrm{~cm}$ y un cuerpo redondeado (Fig. 12: A. 3) pertenece seguramente aún al siglo VII a. de J.C., mientras que el otro (Fig.
12: A. 1) corresponde sin duda a los siglos VII/ VI a. de J.C. Según una apreciación del señor Pierre Rouillard, al que queremos agradecer aquí cordialmente su ayuda, se trata, al ser un fragmento de pared de vaso de arcilla roja con engobe de arcilla negra brillante, del fragmento de un vaso de las islas griegas del siglo $\mathrm{VI}$ a. de J.C. (Fig. 12: A. 5). También Adra-Abdera, con la situación característica en una altura sobre el río Grande, o también río Adra, debió contarse entre los establecimientos fenicios que del siglo VIII al VI se suceden con una densidad sorprendente en la costa andaluza.

Estos datos, para establecer una cronología relativa y absoluta de los platos con borde ancho, se obtuvieron basándose en el material procedente de excavaciones realizadas en la franja costera, que en línea recta dista sólo $40 \mathrm{~km}$, situada entre Toscanos y Almuñécar y, por esto, sólo se aplicaron al principio a este espacio bastante reducido de la costa mediterránea del Sur de España, ya que más allá se carecía de comprobantes seguros sobre un desarrollo paralelo y, por otro lado, diversos hallazgos, sobre todo de los yacimientos de Huelva, parecían oponerse al mismo.

Así, la sepultura 1 de La Joya, en Huelva, que ha de fecharse alrededor del 600 a. de J.C. o poco después, contenía platos con bordes de 3,$7 ; 4,0$ y $4,7 \mathrm{~cm}$ de ancho (Fig. 12: B) ${ }^{6}$ (Orta y Garrido, 1963; 16 s., fig. 6-8; Schubart y Garrido, 1967, 123 s., 126, fig. 3). Al desarrollo de los platos observado en la zona de la costa mediterránea no parece, finalmente, corresponder en absoluto la sepultura 9 de La Joya, que se data en la primera mitad del siglo VI por un escarabeo de Psamético II (595-589) (Gamer-

\footnotetext{
${ }^{6}$ La duda expuesta en Niemeyer y Schubart (1966, 89, n. 59) acerca del carácter cerrado del inventario no tiene ya significación alguna a la vista de los inventarios más recientes, especialmente el de la sepultura 9. Los dibujos de la Fig. 13 se han hecho de las piezas originales. En Orta y Garrido (1963) aparecen ligeras discrepancias entre la descripción y el dibujo. Plato 1: en el texto, ancho de borde $4 \mathrm{~cm}$, según el dibujo 3, $7 \mathrm{~cm}$. Plato 3: en el texto ancho de borde $4 \mathrm{~cm}$, según el dibujo $4,7 \mathrm{~cm}$. El plato 2 tiene según el dibujo un ancho de borde de $3,7 \mathrm{~cm}$. La forma de cuenco con pie (Orta y Garrido, 1963, 19, fig. 8 -plato 7-) no puede, a pesar de su forma de borde muy semejante, $3,7 \mathrm{~cm}$, contarse ya entre los platos propiamente dichos. Lo mismo sucede con el cuenco (Orta y Garrido, 1963, 13, fig. 7.2 -plato 5-) con un ancho de borde de $2,8 \mathrm{~cm}$.

7 El plato de la sepultura 2 de La Joya (Garrido, 1970, fig. 6.2) no puede, lo mismo que los platos de la sepultura 9 (Garrido 1970, fig. 39.4-5), incluirse claramente en las formas de plato. Los datos sobre anchos de borde se han tomado del catálogo (Garrido, 1970, 52 s.), ya que las medidas tomadas de los dibujos son menos seguras.
} 


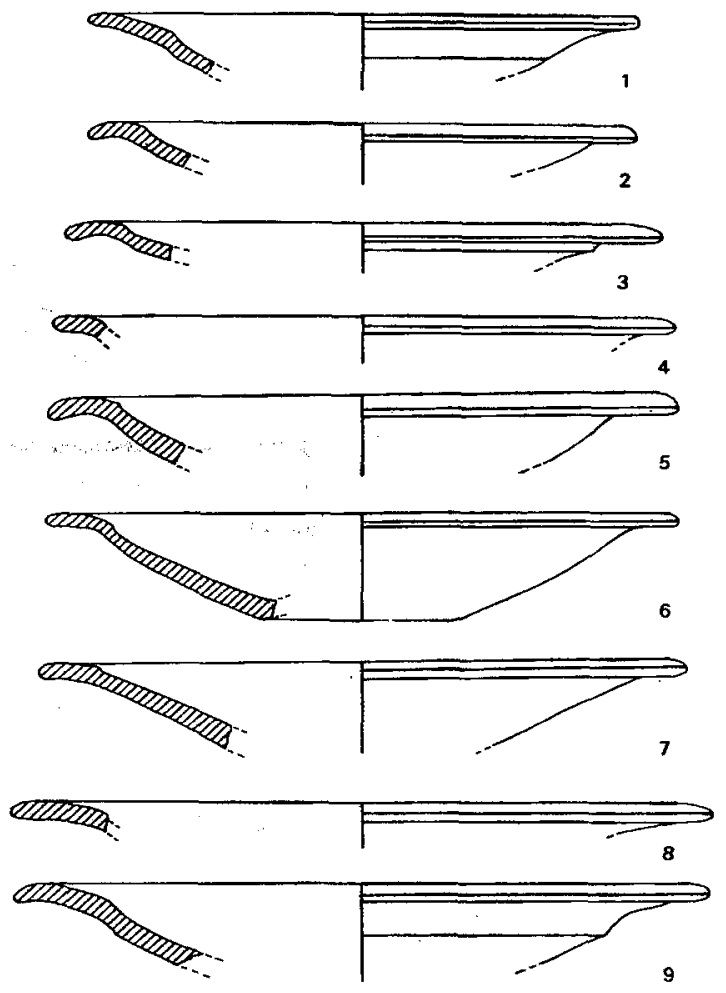

Figura 14: Cabezo de San Pedro (Huelva). 1(L), 2 (A), 3 (F), 4 (1), 5 (D), 6 (B), 7 (C), 8 (E), 9 (J)

Wallert, 1973, 121 s., fig. 1, lám. 14) y que contiene platos con anchos de borde de 2,$0 ; 2,7$; 2,8 y $3,0 \mathrm{~cm}$ (Fig. 13: A), o sea platos con bordes de un ancho sorprendentemente bajo, que por sus valores medios corresponden aproximadamente a los hallazgos de Chorreras, pero a los que hay que fechar sin embargo en el siglo VI a. de J.C. (Garrido, 1970, 39 s., 52 s., figs. 38-39) ${ }^{7}$.

A esta imagen correspondieron por completo los platos (Fig. 13: B) que se encontraron en el poblado del Cabezo de San Pedro, situado en la proximidad del anterior (Blázquez, Luzón, Gómez Toscano y Clauss, 1970, lám. 14). Diez platos tenían sus anchos de borde entre 2,3 y $3,3 \mathrm{~cm}$, habiendo aun de señalarse como medida extrema un plato con un ancho de borde de $1,7 \mathrm{~cm}$. Sólo dos veces están representados en el Cabezo de San Pedro bordes de plato más anchos, 5,4 y $6,2 \mathrm{~cm}$ (Fig. 13: B. 9-15). Por ello, también para las consideraciones que se exponen a continuación, es esencial la observación de que en los platos con borde estrecho del Cabezo de San Pedro y de La Joya se trata de vasos más hondos con una tendencia a formas de cuenco y de que realmente sólo existe un plato plano relacionado con un borde ancho (Fig. 13: B. 9). También otros hallazgos posteriores de platos del $\mathrm{Ca}-$ bezo de San Pedro presentan sin excepción bordes estrechos, con anchos entre 2,2 y 3,9 cm (Fig. 14: 1-9).

De todo esto se sacó la conclusión, de que la zona de validez de la "cronología de los anchos de bordes", está claramente delimitada, aunque quedó sin resolver el carácter de esta delimitación (Niemeyer y Schubart, 1975, 123 n. 178). Podría pensarse que se trata, por ejemplo, de una limitación geográfica, como si al otro lado del estrecho de Gibraltar se hubiese producido un desarrollo peculiar, que no hubiese llegado a proporcionar formas con bordes anchos en la misma cantidad que las hubo más hacia el Este. Con esta conclusión, sin duda alguna infundada, no hubiesen estado de acuerdo los platos ya mencionados de borde notablemente ancho del Cabezo de San Pedro en Huelva, así como tampoco el rico material de hallazgos de Mogador y evidentemente también de Lixus. Además, nuevos hallazgos de estos últimos años desempeñan un importante papel en relacion con lo expuesto anteriormente.

En la misma Huelva (calle de Palos 19-21) apareció un conjunto de fragmentos, encontrado casualmente, en el que, junto a fragmentos de la cerámica gris y sobre todo de la polícroma, había un fragmento de borde de plato que, en un diámetro a reconstruir de 28,0 $\mathrm{cm}$, medía $7,5 \mathrm{~cm}$ de ancho de borde (Clauss com. pers.) 8 .

En el Cerro de la Esperanza, situado también en el término de la ciudad de Huelva, encontraron en un sondeo otros platos de cerámica roja, aunque sólo en fragmentos bastante pequeños (Schubart y Garrido, 1967, 148, fig. $8 \mathrm{a}-\mathrm{k}$ ). Junto a un estrecho borde de $2,5 \mathrm{~cm}$ aparecen sólo fragmentos cuyos anchos de borde no pueden apreciarse. Dos de los bordes tenian con seguridad anchos superiores a 5,2 y $6,0 \mathrm{~cm}$ y se cuentan por tanto entre las formas más tardías. En los hallazgos de superficie hechos en los años 1968 y 1969 en el Cerro de la Esperanza (Fig. 15: A) había tres platos de cerámica roja con bordes particularmente anchos $(6,6 \mathrm{~cm}$ y $7,6 \mathrm{~cm}$, así como de más de

\footnotetext{
${ }^{8}$ Según amable comunicación de K. Claus, de Huelva. Las medidas de otros platos que, ya terminado el manuscrito, no pudieron tenerse en cuenta en las figs. 12 y 13 (Anch. bor$\mathrm{de}=1,5 \mathrm{~cm} ; 1,6 \mathrm{~cm} ; 2,3 \mathrm{~cm} ; 2,7 \mathrm{~cm} ; 2 \times 2,8 \mathrm{~cm} ; 2,9 \mathrm{~cm} ; 2 \mathrm{x}$ $3,5 \mathrm{~cm} ; 3,6 \mathrm{~cm} ; 4,2 \mathrm{~cm} ; 4,3 \mathrm{~cm} ; 4,8 \mathrm{~cm} ; 4,9 \mathrm{~cm} ; 5,7 \mathrm{~cm})$ se deben a Mariano del Amo, director del Museo Arqueológico Provincial de Huelva.
} 

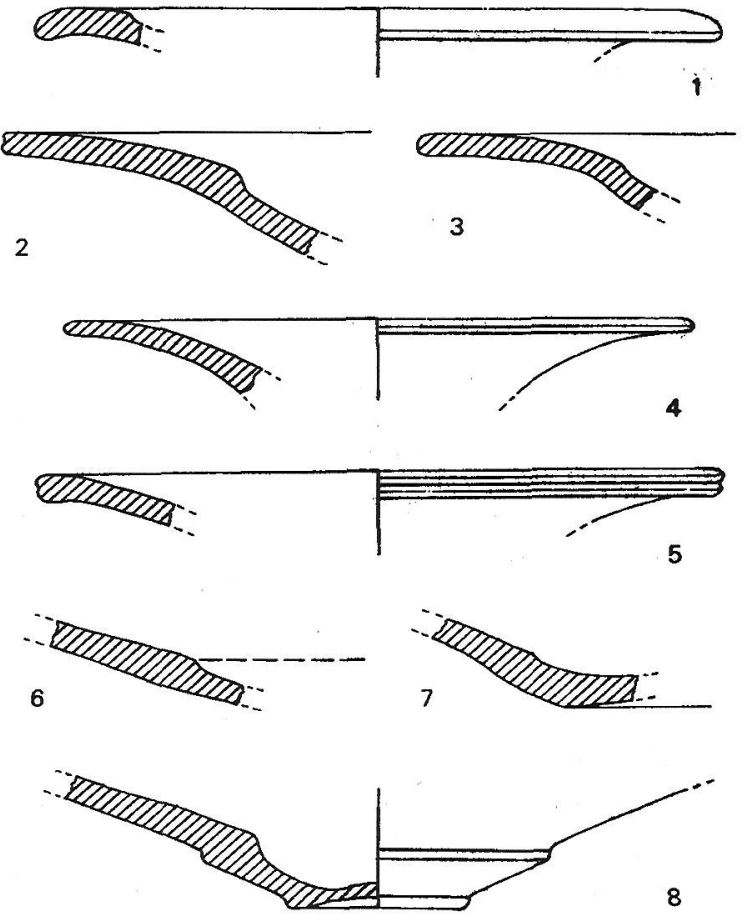

A
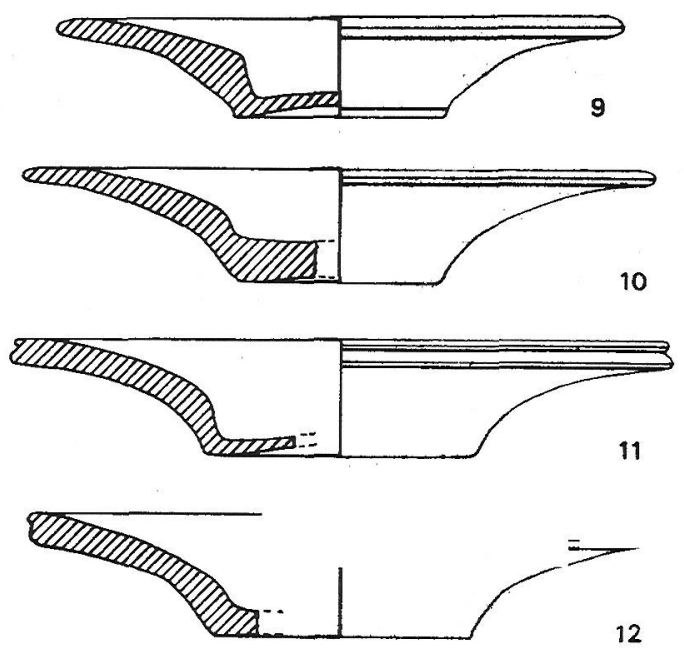

12

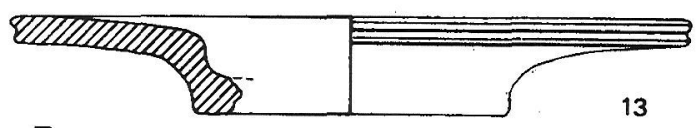

B

Figura 15: A: Cerro de la Esperanza (Huelva). B: Jardín (Torre del Mar, Málaga). Campañas de 1971/1974. 9 (sep. 67, TM 74/231/1), 10 (sep. 57, TM 74/305/1), 11 (sep. 84, TM 4/ 384/2), 12 (sep. 10, TM 71), 13 (sep. 12, TM 71) (Lindemann, Niemeyer y Schubart, 1972, 153s, fig, $15 \mathrm{~g}$ y 16.1 ; MaassLindemann y Schubart, 1975, 185, fig. 3).

$6,4 \mathrm{~cm})$ y sólo uno con borde estrecho $(3,2 \mathrm{~cm})$. Hasta ahora predominan por tanto aquí platos con bordes anchos, aun cuando el escaso número de hallazgos no permita ninguna afirmacion definitiva.
Asimismo, hacia el interior, en la zona montañosa de la provincia de Huelva, en la región minera de Río Tinto, se nota claramente la influencia de este desarrollo hacia formas de plato más recientes, como lo confirma el hallazgo de un plato con un ancho de borde de $6,6 \mathrm{~cm}$ del Cerro Salomón, en el marco de un poblado que debe considerarse como un poblado de mineros en el centro de la zona donde se halla el mineral (Blanco, Luzón y Ruiz Mata, 1970, lám. 22 izq. arriba e izq. 2 fila dcha., fig. 16).

Se conocen asimismo platos con bordes bastante anchos de la necrópolis de influencia fenicia de la Cruz del Negro en Carmona (Sevilla) (Monteagudo, 1953, 356 s., fig. 33 izq. abajo $)^{9}$. Posiblemente hay que incluir también en este inventario los platos de engobe rojo $(3,8$ $\mathrm{cm} ; 4,4 \mathrm{~cm} ; 4,5 \mathrm{~cm} ; 4,5 \mathrm{~cm}$ ) de la colección Bonsor en el castillo de Mairena del Alcor, sin datos exactos sobre su procedencia.

Aun cuando estos hallazgos proceden de una zona que tiene que considerarse tan sólo como de influencia fenicia, aparece ahora como descubrimiento nuevo un poblado fenicio junto al río Guadarranque, sobre el Cerro del Prado, cerca del Cortijo del Sacristán (Cádiz) ${ }^{10}$, poblado que en su situación sobre una colina relativamente baja resulta ser continuación de los establecimientos fenicios antiguos, entre los que nos limitaremos a mencionar Adra, Almuñécar, el Morro de Mezquitilla, Toscanos y Guadalhorce como ejemplos en la costa española. Los cinco fragmentos de platos del establecimiento fenicio del río Guadarranque alcanzan en sus bordes anchos de 5,4 a 7,4 cm y se encuentran así en el cuadro de anchos de borde (Fig. 7) aproximadamente entre Almuñécar y Trayamar, dando la impresión, en una interpretación algo ajustada, de ser un poco más recientes que Almuñécar y tal vez algo más antiguos que Trayamar. Considerando, sin embargo, la vida siempre bastante larga de un poblado y lo fortuito de los hallazgos de superficie hechos hasta ahora, no es posible sacar aun de estos datos una conclusión acerca de

\footnotetext{
${ }^{9}$ Las medidas de los platos de la Cruz del Negro (Carmona, Sevilla) citadas en el texto fueron tomadas por el autor en una visita a la colección Bonsor.

${ }^{10}$ El descubrimiento de este sitio en las proximidades de Carteia (Algeciras, Cádiz) fue realizado por un colaborador de la Casa de Velázquez de Madrid, el Sr. Loïs Menanteau. Estoy muy agradecido al Sr. P. Rouillard, de la Casa de Velázquez y al Sr. A. Tejera, de la Universidad de Sevilla, que me permitieron tomar las medidas de las piezas mencionadas aquí.
} 
la duración total del poblamiento en el establecimiento del río Guadarranque.

Los yacimientos de las costas españolas y marroquíes del Atlántico, ampliados con estos nuevos hallazgos, demuestran claramente que, de acuerdo con la cronologia hasta ahora válida para la costa mediterránea española, se encuentran platos tardíos con bordes anchos también en los establecimientos fenicios hacia Occidente y en el estrecho de Gibraltar, pero igualmente en los poblados indígenas, lo que hace verosímil que la "cronología de anchos de borde" tenga validez también aquí, por lo menos en la zona fenicia. Los poblados de Cabezo de San Pedro y del Cerro de la Esperanza, en Huelva, ofrecen, junto a materiales fenicios, también un considerable tanto por ciento de imitaciones de cerámica fenicia, así como numerosos fragmentos de cerámica a mano. En ambos casos parece que un poblado claramente indígena, sin una influencia fenicia directa aún, precede a los estratos con importación fenicia. Según todas las apariencias, no se trata por tanto de establecimientos fenicios, sino de asentamientos autóctonos, que en un momento determinado experimentaron una influencia fenicia. También las sepulturas de La Joya, construidas como grandes fosas de tierra, destacan brillantemente, con sus ricos objetos de importación, entre los que se encuentran tripodes, calderos y jarros de bronce, objetos grandes de marfil, y con su característica mezcla de platos hechos a mano y de engobe rojo, y aparecen como totalmente distintas frente a las necrópolis fenicias, o sea frente a las sepulturas de cámara de Trayamar o las sepulturas de pozo de Almuñécar, en las que se observa un inventario funerario fenicio puro, que está además fijado claramente por un ritual sepulcral determinado, como sucede también en otros lugares de la costa norteafricana e italiana. La distinción entre las colonias fenicias y los poblados indígenas de influencia fenicia no puede establecerse a base de una pieza aislada, sino basándose en el espectro total de hallazgos. Y, apoyándose en estas observaciones, hay precisamente lugares como el Cabezo de San Pedro, el Cabezo de la Esperanza y la necrópolis de La Joya, asi como el poblado minero del Cerro Salomón, en Río Tinto, que deben considerarse como tartéssicos y no como fenicios (Schubart, 1973, 1 y 1975, 199 s.) ${ }^{11}$.

A la vista de la diferencia existente entre las colonias fenicias, como Mogador, Lixus y Río Guadarranque y los poblados tartéssicos, por lo menos cronológicamente contemporá- neos, entre los que hay que mencionar en primer lugar los distintos Cabezos de Huelva y también el Cerro Salomón, se ponen claramente de manifiesto las limitaciones de la validez de la cronología de los platos basada en el ancho de los bordes; la sucesión de las formas de platos, tal como se observó en la zona entre Toscanos y Almuñécar, parece haber seguido un desarrollo paralelo en las colonias al otro lado del Estrecho de Gibraltar, mientras que los poblados tartéssicos se desarrollaron de un modo peculiar. Alli, las formas fenicias antiguas de platos de borde estrecho, que se adoptaron al principio de la colonización fenicia y del contacto de las culturas fenicia e indigena, se conservaron al parecer en la zona tartéssica con esta misma forma antigua y siguieron haciéndose hasta ya entrado el siglo VI a. de J.C. por alfareros con modelos arcaizantes. Estos talleres arcaizantes pueden haber trabajado o en la región fenicia o -posiblemente un poco más tarde- en la región tartéssica pero, evidentemente, siempre para el mercado y también para el gusto tartéssicos. También aparecen ejemplos del posterior desarrollo de formas fenicias en el mundo tartéssico. El llegar a establecer si estas piezas son objetos de importación o imitaciones, tendrá que ser objeto de un estudio detallado. Que el desarrollo del borde de los platos tendía en general a formas más anchas también en la zona de influencia tartéssica, se puede detectar hasta en la zona del Guadiana, donde por ejemplo en Medellín, en el conjunto 22, en una fecha antigua como el siglo VII a. de J.C., apareció un plato con un ancho de borde de $4,6 \mathrm{~cm}$ y en conjuntos de hallazgos más recientes se encontraron anchos de borde de hasta $6,8 \mathrm{~cm}$ (Almagro Gorbea, 1971, 161 s., 180 s., fig. 4; Almagro Gorbea, $1977)^{12}$

Esta reacción indígena a la influencia exterior, este adoptar espontáneo de la forma extraña en la época del primer contacto y mantener después en lo sucesivo la forma que se apropió, sólo puede resultar de momento verosímil para los platos de cerámica roja. El resultado es, no obstante, importante, aun cuando por un lado- la "cronología de los platos", sólo

\footnotetext{
11 Entre los sitios sólo influidos debió contarse también el poblado de Aljaraque (Huelva) (Blázquez, Luzón y Ruiz Mata, $1969-70,304$ s.) que, según los hallazgos hasta ahora conocidos, tampoco se establece en el siglo VII a. de J.C

12 En Medellin aparecen, junto a los propios platos, desarroIlos posteriores a cuencos con pie, como aparecen también en la sepultura 1 de La Joya.
} 


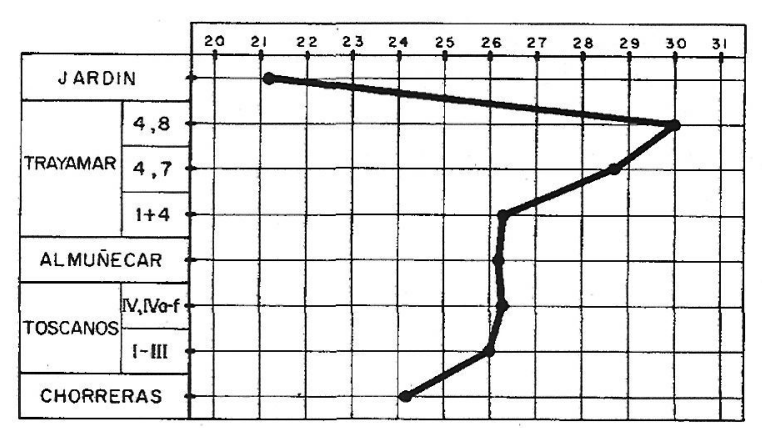

Figura 16: Diámetro medio en $\mathrm{cm}$ de los platos de Chorreras, Toscanos, Almunécar-Laurita, Trayamar y Jardín, donde se observa el progresivo incremento del diámetro medio de los platos desde las etapas más antiguas en Chorreras en el siglo VIII a. de J.C. hasta Trayamar en el siglo VII a. de J.C. y su decrecimiento en Jardín entre los siglos VI-V a. de J.C.

deberá aplicarse en el futuro a las colonias, no al interior "tartéssico", y aun más adentro, donde este error metódico podría llevar a falsos razonamientos, lo que no podemos tratar aquí con detalle. Por otro lado, el resultado nos lleva aparte de la cuestión particular a la vez al problema general: aun cuando las observaciones sólo tienen de momento vigencia para los platos, habría que estudiar hasta qué punto podrían también diferenciarse cronológicamente otras formas fenicias y "tartéssicas" y observarse fenómenos análogos de aceptación y pervivencia, tales como permite sospechar la tendencia general, con lo que podrían finalmente hacerse visibles rasgos esenciales del carácter de la cultura tartéssica.

Con el siglo VI a.C., y paralela a la remisión de la influencia fenicia y al aumento de la cartaginense, se manifiesta una nueva tendencia en el desarrollo de los platos (Arribas y Arteaga, 1976) ${ }^{13}$ : la anchura creciente del borde llegó a ocupar finalmente, como ya había ocurrido en algunas formas de Trayamar (Niemeyer y Schubart, 1975, lám. 21, 709 y 23, 715), casi todo el plato, de tal modo que el plato propiamente dicho quedó reducido a un pequeño rehundido en el centro. Simultáneamente se redujo, en contraposición al desarrollo anterior (Niemeyer y Schubart, 1975, lám. 126, fig. 18 ), el diámetro total del plato, con lo que volvieron a dominar formas más pequeñas, aunque con un borde muy ancho (Fig. 16). Este tipo de plato está muy bien representado, por ejemplo, en la necrópolis de Jardín (Fig. 15: B) (Lindemann, Niemeyer y Schubart, 1972, 156; Maass-Lindemann y Schubart, 1975, 183 y 186). La necrópolis de Jardín parece tener su principio en el siglo VI (¿temprano?) (MaassLindemann y Schubart, 1975, fig. 3a) y lleva a.
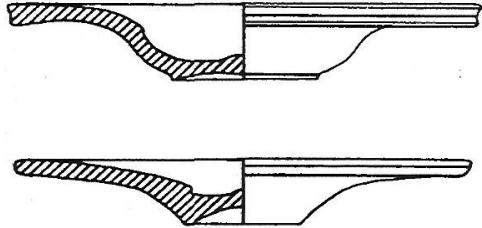

A
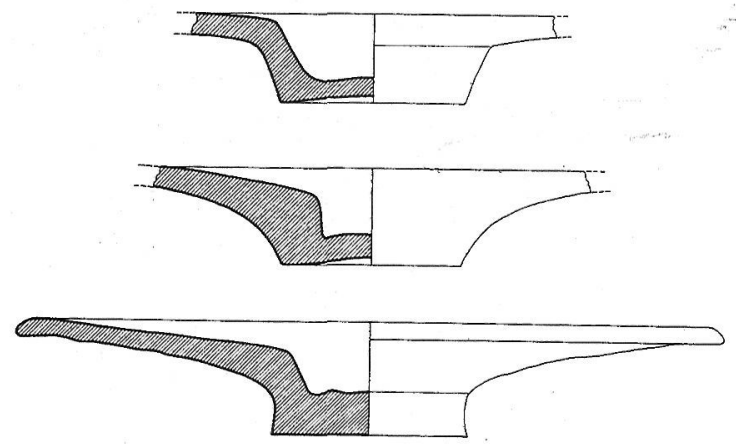

B
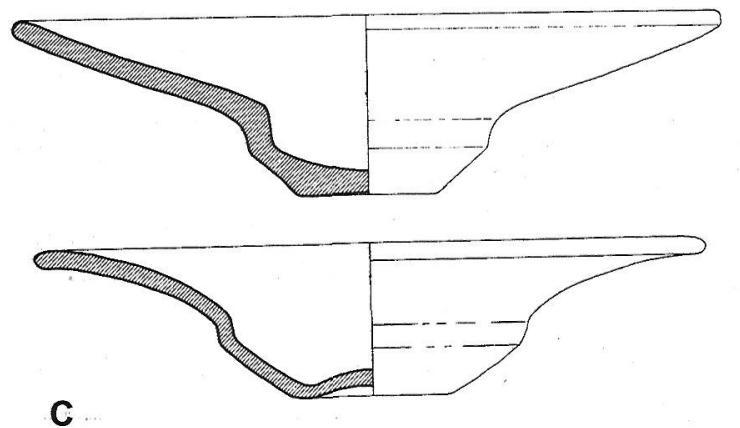

Figura 17: A: Cortijo de las Sombras (Frigiliana, Granada) (Arribas y Wilkins, 1969, fig. 18). B:Alcácer do Sal (Portugal) (Mus. Alcácer do Sal). C: Santa Olaia (Figueira da Foz, Portugal) (Mus. Santos Rocha, Figueira da Foz).

lo largo de su ocupación, en la que son posibles observaciones de estratigrafía horizontal, hasta el siglo IV a. de J.C. (Lindemann, Niemeyer y Schubart, 1972, 156; MaassLindemann y Schubart, 1975, 183, 186). Los platos de la necrópolis de Jardín se componen sólo del fondo, con una base ligeramente entrante, y de un ancho borde, que aquí a veces está acanalado. Ahora, con un diámetro en disminución (Fig. 16), la proporción diámetro/ancho de borde adquiere de nuevo una importancia especial, ya que al cambiar en principio la

${ }^{13}$ El poblado de la desembocadura del río Guadalhorce, muy próximo a Málaga por el Oeste, muestra en su estratigrafia, cómo en su fase más antigua, a finales del siglo VII a. de J.C., que está representada casi toda la escala de tipos de la cerámica roja (lucernas, jarras, pebeteros, platos y cuencos) y cómo en la fase más reciente, en el siglo VI a. de J.C., se interrumpe el desarrollo de esta cerámica, y desde entonces sólo se fabrican platos y cuencos con engobe rojo. 


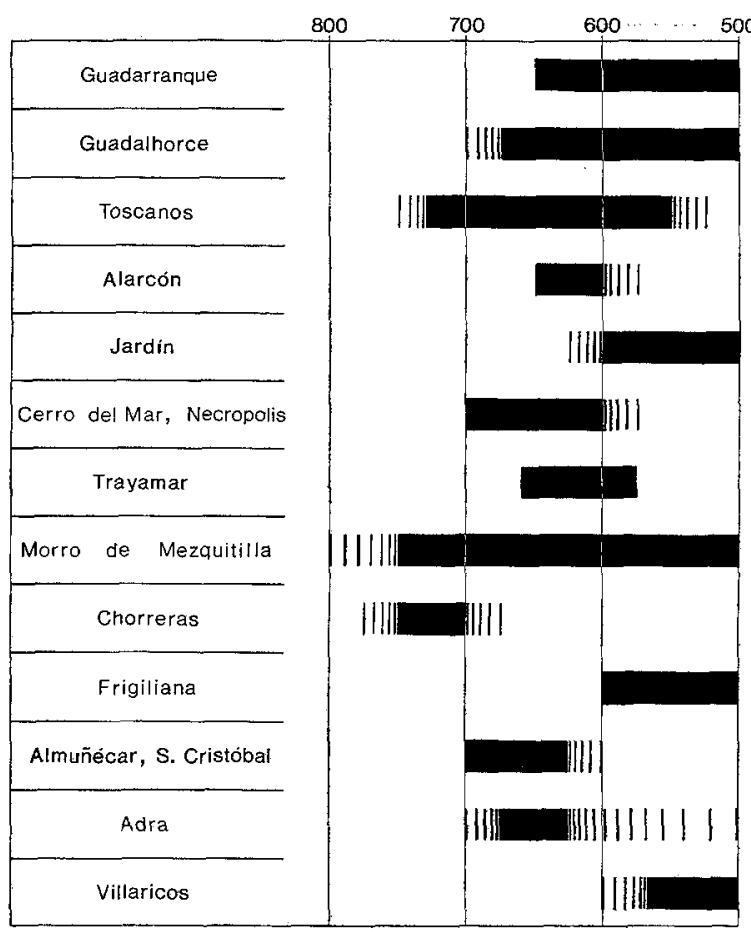

Figura 18: Esquema cronológico de la fundación y ocupación de los asentamientos y necrópolis fenicios occidentales en la costa ibérica meridional, asi como de los lugares púnicos costeros algo más modernos y de los sitios con influencias fenicias. El esquema sirve para apreciar el horizonte de fundación entre los siglos VIII/VII a. de J.C. No se valora la continuidad después del 500 a. de J.C. (Schubart, 1982a, 228, fig. 17).

forma, baja el valor de los datos absolutos de la anchura del borde. La representación gráfica de la distribución del cociente muestra cómo también ahora la tendencia general perceptible en el desarrollo conserva el aumento relativo de la anchura del borde (Fig. 8).

Ejemplos de este proceso se encuentran en la necrópolis de incineración del Cortijo de las Sombras en Frigiliana (Granada) (Arribas y Wilkins, 1969,238 s., fig. 18$)^{14}$, donde los platos volvieron a utilizarse como tapaderas de urnas (Fig. 17: A). Estas formas tardias de platos, que no empezaron hasta el siglo $\mathrm{VI}$ a. de J.C. y siguieron entonces desarrollándose, son bien conocidas de amplias zonas, aunque en general han sido insuficientemente publicadas. Se encuentran tanto en lbiza (Fig. 8) (MaassLindemann com. pers. $)^{15}$, como en Cerdeña (Monte Sirai, Mus. Cagliari; Tharros, Mus. Oristano $)^{16}$, pero presentan ahora rara vez el característico engobe rojo de las formas más antiguas, que evidentemente sólo se conserva por más tiempo en el mediodía ibérico en estos platos y las formas derivadas de ellos (Fig. 17: B y C). Aparece también claramente la semejanza de este tipo de plato con los platos de la serie $M$ del santuario de Tanit en Cartago (Harden, 1937, 83 s., fig. 7 M 1-7), que Cintas relaciona con formas de páteras griegas del siglo IV (Cintas, 1950, 490; Delattre 1899, 3, fig. 4). Pero el desarrollo de los platos propiamente fenicios ha concluido ya en esta época.

Para la cronología, tanto relativa como absoluta, de estos platos fenicios más antiguos de Occidente, la estratigrafía de Motya, publicada en 1964, es en cambio de gran interés. Allí se encontraron cerca de la puerta Sur, en la fase I, un plato con un ancho de borde de $3,2 \mathrm{~cm}$, en la fase lla otro plato con $4,3 \mathrm{~cm}$ de ancho de borde y en la puerta Norte, en la fase II, dos platos con anchos de borde de 5,0 y 5,3 $\mathrm{cm}$ (Isserlin et alii, 1962-63, $84 \mathrm{~s}$., fig. 9. 6, 10.7, 14. 1-2, fig. 10. 1). El desarrollo se extiende aquí desde los siglos VIII/VII hasta el VI a. de J.C.

También en la Madre Patria fenicia parecen haber tenido bordes estrechos los platos de los siglos IX/VIII a. de J.C., aun cuando la comparación con los platos del Occidente fenicio, con bordes por regla general claramente marcados, no está asegurada en todos los casos (Niemeyer y Schubart, 1975, 42, fig. 35). Las muy recientes excavaciones de Pritchard (1975, fig. 18.4-5, 7, 19-20, 22, 47.4-5) en Sarepta ofrecen buenos paralelos, aunque el desarrollo de las formas que aquí interesan no puede seguirse en detalle basándose sólo en los datos de la publicación y en el escaso número de sus ilustraciones. Pero resulta evidente

\footnotetext{
${ }^{14}$ La necrópolis de Frigiliana parece pertenecer al siglo $\mathrm{VI}$ a. de J.C., mientras que la necrópolis de Jardín conoce también formas más recientes.

15 El autor está muy agradecido a la Dra. Maass-Lindemann por haberle permitido examinar su material. Los datos de cocientes de lbiza se deben a referencia suya.

${ }^{15}$ Por ejemplo, en Monte Sirai en el Museo de Cagliari (entre otros un plato con líneas radiales en el borde). En 1974 se pudo medir en Tharros, en el Museo Oristano, 7 platos de Tharros, de los cuales solamente uno tenía un barniz rojo de poca calidad: 1: Diám. máx:: $21 \mathrm{~cm}$. Anch. borde: $6 \mathrm{~cm}$. 2 Diám. máx: $19 \mathrm{~cm}$. Anch. borde: $5,7 \mathrm{~cm}$. 3: Diám. máx.: 23 $\mathrm{cm}$. Anch. borde: $6,8 \mathrm{~cm}$. 4: Diám. máx.: $21 \mathrm{~cm}$. Anch. borde: $6,5 \mathrm{~cm}$. 5: Diám. máx.: $22 \mathrm{~cm}$. Anch. borde: $6,5 \mathrm{~cm} .6$ Diám. máx.: $19 \mathrm{~cm}$. Anch. borde: $6,0 \mathrm{~cm}$. 7: Diám. máx: 18,5 $\mathrm{cm}$. Anch. borde: $6,5 \mathrm{~cm}$. Los bordes, en general, anchos, pertenecen a platos de diámetro relativamente pequeño, así que la relación entre diámetro y anchura del borde sería 28 , $32(2 x), 33,34(2 x)$ y 35 . Un plato inédito, de la tumba de Bithia, datado por una importación etrusca de inicios del siglo VI a. de J.C., información que agradezco a Giovanni Tore, se encontraria tipológicamene entre las formas de plato más recientes de Trayamar y los platos de Jardín. Cf. también el material en el Museo de Sassari.
} 


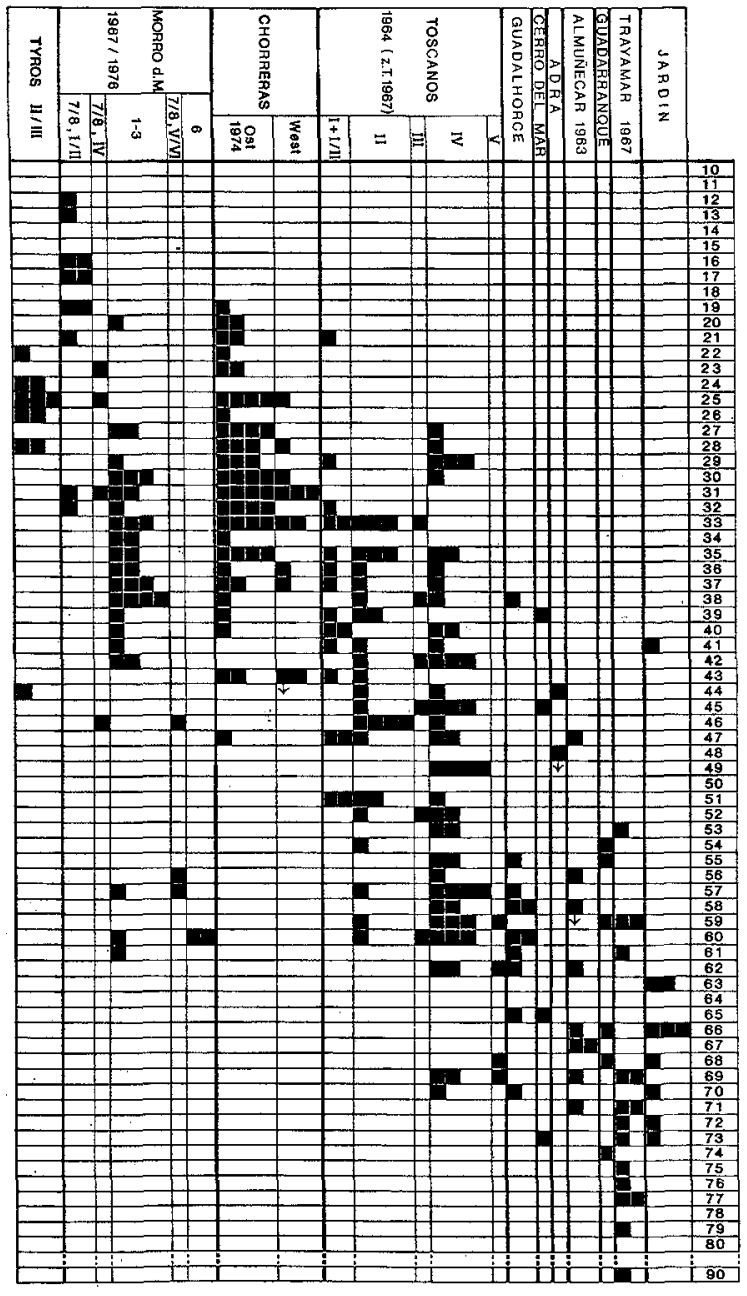

Figura 19: Platos de cerámica roja con anchos del borde en $\mathrm{mm}$ de los asentamientos fenicios occidentales, y otros con influencias púnicas algo más modernos, en la costa meridional de la Península Ibérica. Platos de los estratos II y III de Tiro como comparación, con alrededor de $2,5 \mathrm{~cm}$, y un solo caso con $4,4 \mathrm{~cm}$ en el estrato II, que pertenecen al último tercio del siglo VIII a. de J.C. y ofrecen un punto fijo más de partida para la datación absoluta (Schubart, 1982a, 229, fig. 18).

que las formas de plato $X 5$ y $X 6$ de bordes estrechos $(1,8$ a $2,4 \mathrm{~cm})$ aparecen aun en los estratos D1 y C2 (s. VIII/VII a. de J.C.), aún cuando sus representantes más antiguos alcanzan los finales de la Edad del Bronce. El tipo de plato $X 9$, discrepante en su forma, con bordes más anchos $(3,0$ a $3,3 \mathrm{~cm})$, pero también más inclinados, parece no encontrarse más que en los estratos $G$ a $E^{\prime}$, que corresponden al siglo $X$ a. de J.C. O a finales del $2^{\circ}$ milenio a.C. (Pritchard, 1975, 70.86, 93, 107, 109, 111, 113). Publicaciones posteriores ayudarán sin duda a suplir la falta de material de comparación existente precisamente para el Próximo Oriente.

Con la observación de la formación del borde, relacionándola también con el diámetro del plato, parece haberse encontrado un criterio cronológico importante para conocer el desarrollo de las formas de platos fenicios de Occidente, de tal modo que el plato no sólo se incluye en el cuadro de tipos de la cerámica fenicio-púnica, sino que hay que considerarlo como una de las formas cronológicas fundamentales (Fig. 18; Fig. 19). El plato debe esta prioridad, por un lado, a su gran frecuencia en los poblados y, por otro, a su utilización como elementos del ajuar sepulcral y como ofrenda funeraria. Con el considerable aumento que es de esperar experimente el hallazgo de materiales en futuras investigaciones, el plato fenicio de Occidente debería conservar este importante papel y habría que esperar que a su lado pudiesen situarse en mayor número que hasta ahora, otras formas con igual valor para el establecimiento de cronologías.

\author{
Prof. Hermanfrid Schubart \\ Gickelhof, 7 \\ 35282 Rauschenberg (Alemania)
}

\section{BIBLIOGRAFÍA}

ALMAGRO GORBEA, M., 1971: "La necrópolis de Medellín (Badajoz). Aportaciones al estudio de la penetración del influjo orientalizante en Extremadura", Noticiario Arqueológico Hispano, 16, 161-202.

ALMAGRO GORBEA, M., 1972: "Los dos jarros paleopúnicos del Museo Arqueológico Nacional hallados en la Casa de la Viña (Torre del Mar)", Madrider Mitteilungen, 13; 172183.

ALMAGRO GORBEA, M., 1977: El Bronce Final y el Periodo Orientalizante en Extremadura, Bibliotheca Praehistorica Hispana 14, Madrid.

ARRIBAS, A. y WILKINS, J., 1969: "La necrópolis fenicia del Cortijo de las Sombras (Frigiliana, Málaga)", Pyrenae, $5,185-244$

AUBET, Ma ${ }^{a}$.E., MAASS-LINDEMANN, G. y SCHUBART, H., 1975: "Chorreras. Eine phönizische Niederlassung östlich der Algarrobo-Mündung”, Madrider Mitteilungen, 16, 137178.

AUBET, Ma E., MAASS-LINDEMANN, G. y SCHUBART,H., 1979: "Chorreras. Un establecimiento fenicio al este de la desembocadura del Algarrobo", Noticiario Arqueológico Hispánico, 6, 89-138.

BARCELÓ, J.C. ET ALII, 2001: "Análisis estadistico de la variabilidad de los platos fenicios en el sur de la Península Ibérica", Congreso Internacional de los Estudios Feniciopúnicos, Cádiz, 1459 ss.

BISI, A.M ${ }^{a}$, , 1970: La ceramica punica. Aspetti e problemi, Napoli.

BLÁZQUEZ, J.Ma., LUZÓN, J.M Ma . y RUIZ MATA, D., 196970: "La factoría púnica de Aljaraque en la Provincia de Huelva", Noticiario Arqueológico Hispánico, 13-14, 304331.

BLÁZQUEZ, J.Ma., LUZÓN, J.Ma ., GÓMEZ TOSCANO, F. y KLAUSS, C., 1970: Las cerámicas del Cabezo de S. Pedro. Huelva Arqueológica, 1, Huelva. 
CINTAS, P., 1950: Céramique punique, Paris

DELATTRE, R.P., 1899: Carthage. "La nécropole punique voisine de Sainte-Monique, Second mois des Fouilles", Cosmos, Février 1898, 1-23.

FERNÁNDEZ GÓMEZ, F., 1971:"Recensión de A.M" Bisi, La ceramica punica. Aspetti e problemi, Napoli, 1970", Trabajos de Prehistoria, 28, 421-423.

FERNÁNDEZ-MIRANDA, M. y CABALLERO ZOREDA, L., 1975: Abdera. Excavaciones en el Cerro de Montecristo (Adra, Almería), Excavaciones Arqueológicas en España, 85, Madrid.

GAMER-WALLERT, I., 1973: "Der Skarabäus vom Cabezo de la Joya in Huelva", Madrider Mitteilungen, 14, 121-126.

GARRIDO ROIZ, J.P., 1970: Excavaciones en la necrópolis orientalizante de La Joya, Huelva $\left(1^{a}\right.$ y $2^{a}$ Campañas $)$, Excavaciones Arqueológicas en España, 71, Madrid.

HARDEN, D.B., 1937: "The pottery from the Precinct of Tanit at Salammbo, Carthage", Iraq, 4, 59-89.

ISSERLIN, B.S.J., MACNAMARA, E., COLDSTREAM, J.N., PIKE, G., DU PLAT TAYLOR, J. y SNODGRASS, A.M., 1964: Motya, a Phoenician-Punic Site near Marsala, Sicily. Preliminary Report of the Leeds-London-Fairleigh Dickinson Expedition, 1961-63, The Annual of Leeds University Oriental Society, 4, 1962-63.

JODIN, A., 1966: Mogador. Comptoir phénicien du Maroc atlantique, Tanger.

LINDEMANN, G., NIEMEYER, H.G. y SCHUBART, H., 1972: "Toscanos, Jardin und Alarcón. Vorbericht über die Grabungskampagne 1971", Madrider Mitteilungen, 13, 125-157.

MAASS-LINDEMANN, G., 1982: "Die Entwicklung der westphönikischen Keramik im 7. und 6. Jh. v. Chr. Dargelegt an importdatierten Grabfunden", Toscanos. Die westphönikische Niederlassung an der Mündung des Río de Vélez. Lieferung 3: Grabungskampagne 1971 und die importdatierte westphönikische Grabkeramik des 7./6. Jhs. v. Chr, Madrider Forschungen, 6 (3), Berlin.

MAASS-LINDEMANN, G., en prensa: Die Keramik der Gründungsphase des 8. Jhs. v. Chs., Publicaciones del Instituto Arqueológico Alemán. Madrid.

MAASS-LINDEMANN, G. y SCHUBART, H. 1975: “Jardín. Vorbericht über die Grabung 1974 in der Nekropole des 6./5. Jahrhunderts v. Chr.", Madrider Mitteilungen, 16, 179-186.

MAASS-LINDEMANN, G. y SCHUBART, H. 1979: "Jardín. Informe preliminar sobre las excavaciones de 1974", Noticiario Arqueológico Hispánico, 6, 139-149 y 158-168.

MAYET, Fr. y TAVARES DA SILVA, C., avec la collaboration de MAKAROUN, Y., 2000: Le site phénicien d'Abul (Portugal).Comptoir et sanctuaire, Paris.

MONTEAGUDO, L., 1953: "Álbum gráfico de Carmona" por G. Bonsor", Archivo Español de Arqueología, 26, 356-370.

NIEMEYER, H.G., (ED.), 1982: Phönizier im Westen, (Köln, 1979), Madrider Beiträge 8, Mainz am Rhein.

NIEMEYER, H.G. y SCHUBART, H., 1968: "Toscanos und Trayamar. Vorbericht über die Grabungskampagne 1967”, Madrider Mitteilungen, 9, 76-105.

NIEMEYER, H.G. y SCHUBART, H., 1969: Toscanos. Die altpunische Faktorei an der Mündung des río de Vélez. I. Grabungskampagne 1964, Madrider Forschungen 6/1, Berlín.

NIEMEYER, H.G. y SCHUBART, H., 1971: "Excavaciones paleopúnicas en la zona de Torre del Mar 1967", Noticiario Arqueológico Hispánico, 13-14, 353-383.

NIEMEYER, H.G. y SCHUBART, H., 1975: Trayamar. Die phönizischen Kammergräber und die Niederlassung an der Algarrobo-Mündung. Madrider Beiträge 4, Mainz am Rhein.
NIEMEYER, H.G. y SCHUBART, H., 1976: Trayamar. Los hipogeos fenicios y el asentamiento en la desembocadura del rio Algarrobo, Excavaciones Arqueológicas en España 90. Madrid.

ORTA, E. y GARRIDO, J.P,. 1963: La tumba orientalizante de "La Joya" (Huelva), Trabajos de Prehistoria 11. Madrid.

PELLICER CATALÁN, M., 1963a: Excavaciones en la necrópolis púnica 'Laurita' del Cerro de San Cristóbal (Almuñécar, Granada), Excavaciones Arqueológicas en España 17, Madrid

PELLICER CATALÁN, M., 1963b: "Ein altpunisches Gräberfeld bei Almuñécar (Prov. Granada)", Madrider Mitteilungen, 4, 9-38.

PRICHARD, J.B., 1975: Sarepta. A Preliminary Report on the Iron Age, Philadelphia.

SCHUBART, H., 1969: "Colonias fenicias en la región de Málaga", Arbor, 280, $37 \mathrm{~s}$.

SCHUBART, H., 1973: "Phönizische Niederlassungen an der spanischen Küste und ihre Beziehungen zum Hinterland", Studien über frühe Tierknochenfunde von der Iberischen Halbinsel, 4, 1-8.

SCHUBART, H., 1975: "Las excavaciones de Torre del Mar y el panorama arqueológico de las fundaciones de colonias fenicias en la costa mediterránea de la Península lbérica", L Aniversario de la fundación del laboratorio de arqueologia 1924-1974. Papeles del Laboratorio de Arqueologia de Valencia, 11, 199-206.

SCHUBART, H., 1982a: "Phönizische Niederlassungen an der Iberischen Südküste", Madrider Beiträge, 8, 207-231.

SCHUBART, H., 1982b: "Asentamientos fenicios en la costa meridional de la Península Ibérica”, Huelva Arqueológica, 6, 71-99.

SCHUBART, H. y GARRIDO, J.P., 1967: "Probegrabung auf dem Cabezo de la Esperanza in Huelva 1967", Madrider Mitteilungen, 8, 123-157.

SCHUBART, H., NIEMEYER, H.G. y LINDEMANN, G., 1972: "Toscanos, Jardín y Alarcón. Excavaciones de 1971", Noticiario Arqueológico Hispánico, Arqueología, 1, 9-41.

SCHUBART, H., NIEMEYER, H.G. y PELLICER, M., 1969: Toscanos. La factoría paleopúnica en la desembocadura del río Vélez, Excavaciones Arqueológicas en España 66, Madrid.

TARRADELL, M. y FONT, M., 1974: Eivissa cartaginesa, Barcelona.

VUILLEMOT, G., 1955: "La nécropole punique du phare dans l'lle Rachgoun (Oran)", Libyca, Archaeologie-Epigraphie, $3(1), 6-76$. 